\title{
A Positive Feed Forward Loop between Wnt/ $\beta$-Catenin and NOX4 Promotes Silicon Dioxide-Induced Epithelial-Mesenchymal Transition of Lung Epithelial Cells
}

\author{
Jia Ma, ${ }^{1}$ Qian Cai, ${ }^{1,2}$ Dandan Yang, ${ }^{1}$ Jiali Yang, ${ }^{1}$ Jing Xue, ${ }^{3}$ Miao Yu, ${ }^{1}$ Yingxue Liu, ${ }^{1}$ \\ Fucheng Ma, ${ }^{1}$ Feng Li $\mathbb{D},{ }^{3}$ and Xiaoming Liu $\mathbb{C}^{1,4}$ \\ ${ }^{1}$ Key Laboratory of Ministry of Education for Conservation and Utilization of Special Biological Resources in the Western, College of \\ Life Science, Ningxia University, Yinchuan, Ningxia 750021, China \\ ${ }^{2}$ Key Laboratory of Environmental Factors and Chronic Disease Control, School of Public Health, Ningxia Medical University, \\ Yinchuan 750004, China \\ ${ }^{3}$ General Hospital of Ningxia Medical University, Yinchuan, Ningxia 750004, China \\ ${ }^{4}$ Department of Anatomy and Cell Biology, University of Iowa, Iowa City, Iowa 52242, USA
}

Correspondence should be addressed to Feng Li; li76luo77@126.com and Xiaoming Liu; erc1080@163.com

Received 2 August 2020; Revised 8 November 2020; Accepted 12 November 2020; Published 9 December 2020

Academic Editor: Emiliano Barreto

Copyright ( 2020 Jia Ma et al. This is an open access article distributed under the Creative Commons Attribution License, which permits unrestricted use, distribution, and reproduction in any medium, provided the original work is properly cited.

\begin{abstract}
Silicosis is a chronic fibrotic lung disease caused by the accumulation of silica dust in the distal lung. Canonical Wnt signaling and NADPH oxidase 4 (NOX4) have been demonstrated to play a crucial role in the pathogenesis of pulmonary fibrosis including silicosis. However, the underlying mechanisms of crosstalk between these two signalings are not fully understood. In the present study, we aimed to explore the interaction of Wnt/ $\beta$-catenin and NOX4 of human epithelial cells in response to an exposure of silica dust. Results demonstrated an elevated expression of key components of Wnt/ $\beta$-catenin signaling and NOX4 in the lungs of silicon dioxide- $\left(\mathrm{SiO}_{2}-\right)$ induced silicosis mice. Furthermore, the activated $\mathrm{Wnt} / \beta$-catenin and NOX4 signaling are accompanied by an inhibition of cell proliferation, an increase of ROS production and cell apoptosis, and an upregulation of profibrogenic factors in BEAS-2B human lung epithelial cells exposed to $\mathrm{SiO}_{2}$. A mechanistic study further demonstrated that the Wnt3a-mediated activation of canonical Wnt signaling could augment the $\mathrm{SiO}_{2}$-induced $\mathrm{NOX} 4$ expression and reactive oxygen species (ROS) production but reduced glutathione (GSH), while Wnt inhibitor DKK1 exhibited an opposite effect to Wnt3a. Vice versa, an overexpression of NOX4 further activated $\mathrm{SiO}_{2}$-induced $\mathrm{Wnt} / \beta$-catenin signaling and NFE2-related factor 2 (Nrf2) antioxidant response along with a reduction of GSH, whereas the shRNA-mediated knockdown of NOX4 showed an opposite effect to NOX4 overexpression. These results imply a positive feed forward loop between Wnt/ $\beta$-catenin and NOX4 signaling that may promote epithelial-mesenchymal transition (EMT) of lung epithelial cells in response to an exposure of silica dust, which may thus provide an insight into the profibrogenic role of $\mathrm{Wnt} / \beta$-catenin and NOX 4 crosstalk in lung epithelial cell injury and pathogenesis of silicosis.
\end{abstract}

\section{Introduction}

Silicosis is a fatal occupational chronic fibrotic lung disease caused by long-term exposure to respirable crystalline silica (silicon dioxide $\left(\mathrm{SiO}_{2}\right)$ ) dust that was ultimately deposited in distal airways $[1,2]$. Due to the negligence and failure to control the risk of excessive silica exposure in modern industry and working activities using high-powered hand tools, such as denim sandblasting, jewellery polishing, artificial stone engineering, dental trimming, building constructing, and highway repairing, many developing countries including China are experiencing the reemergence of silicosis [3-5]. Unlike silicosis derived from the long-term silica exposure in traditional occupations such as mining, silica-related diseases in modern industries are characterized by an acute and accelerated progression owing to high-intensity silica 
dust concentrations and oxidative stress over a short time period [3].

Silicosis is currently an incurable disease, and its pathogenesis remains incompletely understood. Etiologically, the inhalation and deposition of silica dust induce inflammatory responses and the production of reactive oxygen species (ROS), which in turn lead to the epithelial-mesenchymal transition (EMT) and development of pulmonary fibrosis, which can be characterized by massive extracellular matrix (ECM) deposition and fibroblast proliferation, and myofibroblast differentiation [6]. Similar to that demonstrated in other chronic lung diseases, the pathogenesis of silicosis is controlled by interactions between various cellular signaling pathways [7-10]. Among them, the wingless-type MMTVintegration site $(\mathrm{Wnt}) / \beta$-catenin signaling, a well-known critical cellular signaling pathway in embryonic development and tissue homeostasis, is reactivated in many chronic pulmonary diseases, including silicosis [8, 9, 11-13]. A blocking of $\mathrm{Wnt} / \beta$-catenin signaling alleviated the lung inflammation and fibrosis in silica-induced mouse and rat silicosis models [14-16]. These studies suggested that $\mathrm{Wnt} / \beta$-catenin is a key driver in the initiation and development of silicosis.

In addition to the dysregulation of cellular signaling activities, the inhalation of silica dust also causes oxidative stress by the production of reactive oxygen species (ROS) that contributes to chronic airway inflammation and epithelial cell injury [17]. Indeed, ROS are important mediators with a variety of biological functions, such as cell proliferation and differentiation, cell migration, and immune regulation [18]. ROS are also required for the maintenance and differentiation of primary lung fibroblasts for lung tissue homeostasis [19]. However, a continuously excessive production of ROS (oxidative stress) in the lung by nicotinamide adenine dinucleotide phosphate (NADPH) oxidase (NOX) may result in tissue injury and dysregulated injury/repair and ultimately lead to chronic pulmonary diseases, such as pulmonary fibrosis $[19,20]$. In addition, exposure to silica dust was demonstrated to induce ROS production and lung injury in animal models $[17,21]$, suggesting a pathogenetic role of ROS in the development of silicosis.

The major ROS are generated by NOXs, membranebound enzyme complexes present in both phagocytes and nonphagocytic cells [22]. There are seven NOX homologs identified to date, namely, the NOX1-5 and dual oxidases 1 and 2 (DUOX1 and DUOX2) [18]. Despite the fact that these NOX proteins have abilities to produce superoxide anions, they possess distinct roles. Among them, NOX4 has a unique role and is broadly expressed in pulmonary artery endothelial cells and smooth muscle cells, airway epithelial cells, and pulmonary interstitial myofibroblasts. NOX4 is able to produce superoxide and generate extracellular $\mathrm{H}_{2} \mathrm{O}_{2}$ after a catalase activity $[23,24]$. Moreover, NOX4 is most commonly implicated in profibrotic processes of multiple organs, including the liver and lung. In this regard, NOX4 is the only isoform of NOX proteins highly upregulated in the epithelial cells and myofibroblasts of lungs in idiopathic pulmonary fibrosis (IPF) patients $[25,26]$. These clinical findings were corroborated by the fact that NOX4-deficient mice developed significantly less bleomycin-induced pulmonary fibrosis and alveolar epithelial cell death [25], suggesting the importance of NOX4 in the pathogenesis of pulmonary fibrosis. In addition, the inhibition of NOX4 attenuated pulmonary fibrosis in a bleomycin-induced rat lung fibrosis model [27]. Mechanistically, the excessive expression of NOX4 and production of ROS induce epithelial cell death, myofibroblast differentiation, and ECM deposition [23, 25].

In view of the widespread evidence for hyperactivated NOX4 and Wnt/ $\beta$-catenin signaling in pulmonary fibrotic procession, and involvements of silica-induced ROS production in pathogenesis of silica-related diseases, we hypothesized that the interaction between the NOX4 and Wnt/ $\beta$-catenin signaling may contribute to the pathogenetic process of silica-related lung disease. However, the link between $\mathrm{Wnt} / \beta$-catenin signaling and NOX4-mediated ROS in the development of silicosis has not been established. Here, we demonstrate that a positive feed forward loop of NOX4 and $\mathrm{Wnt} / \beta$-catenin signaling promotes the fibrotic property in airway epithelial cells in response to silica dust exposure.

\section{Materials and Methods}

2.1. Preparation of Silica $\left(\mathrm{SiO}_{2}\right)$ Particles. Silica $\left(\mathrm{SiO}_{2}\right.$, mesoporous, $2 \mu \mathrm{m}$ particle size, CAS number 7631-86-9) and silicon dioxide ( $\sim 99 \% \mathrm{SiO}_{2}, 0.5-10 \mu \mathrm{m}$ particle size, $14808-60-7$ ) were products of Sigma-Aldrich (St. Louis, MO, USA). The $\mathrm{SiO}_{2}$ particles were baked at $200^{\circ} \mathrm{C}$ for $2 \mathrm{~h}$ to inactivate endotoxin prior to being suspended in saline at a concentration of $100 \mathrm{mg} / \mathrm{mL}$. The $\mathrm{SiO}_{2}$ saline stock was further dispersed for $15 \mathrm{~min}$ in a water bath sonicator followed by being triturated through a $25 \mathrm{G}$ needle before use as described in the previous report [28].

2.2. Generation of $\mathrm{SiO}_{2}$-Induced Silicosis Mouse Model. The protocol and use of mice were approved by the Laboratory Animal Committee of College of Life Science at Ningxia University, in accordance with guidelines of the National Institutes of Health Guide for the Care and Use of Laboratory Animals (NXULS20180123-3). For the generation of silicosis lungs in mice, the protocol, dose, and delivery method described in the previous study were employed with a slight modification [28]. Twelve healthy C57BL/6 mice with 6-8 weeks of age, male and female by half, were purchased from Beijing Vital River Laboratory Animal Technology Co. Ltd. (Beijing, China). All of the mice were housed in a Special Pathogen-Free (SPF) facility with a 12/12 h light/dark cycles and water ad libitum at Ningxia Medical University (Yinchuan, China). The male and female mice were randomly divided into two groups (3 male and 3 female mice per group): (1) saline control group: mice were intratracheally instilled $50 \mu \mathrm{L}$ of saline and (2) silica group: animals were intratracheally instilled $50 \mu \mathrm{L}$ of $50 \mathrm{mg} / \mathrm{mL}$ silica in saline (>99\% $\mathrm{SiO}_{2}$, the dust particle size was $0.5-10 \mu \mathrm{m}$, and $80 \%$ of the particles were $1-5 \mu \mathrm{m})$. The mice were euthanized at 2 weeks (14 days) after the exposure of silica dust for pathohistological and molecular analysis [28].

2.3. Cell Cultures and Infection of Recombinant Adenovirus. A human bronchial epithelial cell line, BEAS-2B (ATCC 
CRL-9609), was purchased from American Type Culture Collection (ATCC) (Manassas, VA, USA). Cells were cultured in DME/F12 (50\%/50\% volume) basal medium (HyClone) supplemented with $10 \%$ Fetal Bovine Serum (FBS) (Ausbian, Cat No. VS500T, Australia) in a humidified atmosphere of $95 \%$ air- $5 \%$ carbon dioxide $\left(\mathrm{CO}_{2}\right)$ at $37^{\circ} \mathrm{C}$. When cells reached $\sim 80 \%$ confluence, they were utilized for infection with adenoviral vectors and/or exposed to different concentrations of $\mathrm{SiO}_{2}$ dust for various time periods for analysis. Adenoviral vectors expressing mouse Wnt3a (AdWnt3a), Ad.shRNA-NOX4 and adenoviral backbone vector control (AdC) were kindly provided by Dr. John F. Engelhardt at the University of Iowa (Iowa City, Iowa, USA) [29]. Adenoviral vector expressing human NOX4 (AdNOX4) was a product of Applied Biological Materials Inc. (Cat. No. 114456A; Richmond, Canada). Adenoviral vector AdDKK1, which expressed mouse DKK1, was generated by Shanghai Genechem Co., Ltd. (Shanghai, China). BEAS-2B cells were infected with adenoviral vectors at a multiplicity of infection of 1000 for $24 \mathrm{~h}$ before they were cultured for an additional $48 \mathrm{~h}$ in the presence or absence of $\mathrm{SiO}_{2}(2 \mu \mathrm{m}$ in size $)$ at a concentration of $100 \mu \mathrm{g} / \mathrm{cm}^{2}$. The cells were then harvested for analysis. For the treatment of ROS scavenger $\mathrm{N}$-acetyl-L-cysteine (NAC), cells were refreshed with media containing $10 \mathrm{mmol} / \mathrm{L}$ of NAC for $2 \mathrm{~h}$ before $\mathrm{SiO}_{2}$ was added into the culture media. The cells were then continuously cultured in the presence of NAC for an additional $24 \mathrm{~h}$ or $48 \mathrm{~h}$ prior to being harvested for analysis.

2.4. Cell Viability Assay. The cell viability was accessed using the Cell Counting Kit- (CCK-) 8 as per the manufacturer's instruction (Dojindo Molecular Technologies, Kumamoto, Japan). Briefly, the cells $\left(5 \times 10^{3} /\right.$ well $)$ were seeded in a 96well plate and grown overnight prior to exposure to silica dust $(2 \mu \mathrm{m}$ particle size $)$ at a density of $0,50,100,150$, or $200 \mu \mathrm{g} / \mathrm{cm}^{2}$ for 24 or $48 \mathrm{~h}$. Subsequently, $10 \mu \mathrm{L}$ of CCK8 solution was added to each well, and the plates were incubated at $37^{\circ} \mathrm{C}$ for an additional $2 \mathrm{~h}$. The absorbance of wavelength at $450 \mathrm{~nm}$ was read on a microplate reader (BioTek, Winooski, VT, USA). The relative cell viability was expressed as the percentage of $\left(\mathrm{OD}_{\mathrm{SiO}_{2} \text {-cells }}-\mathrm{OD}_{\mathrm{SiO}_{2} \text {-medium }}\right) /\left(\mathrm{OD}_{\text {cells }}-\right.$ $\left.\mathrm{OD}_{\text {medium }}\right) \times 100$, where the $\mathrm{OD}_{\mathrm{SiO}_{2} \text {-cells }}, \mathrm{OD}_{\mathrm{SiO}_{2} \text {-medium, }}$, $\mathrm{OD}_{\text {cells, }}$, and $\mathrm{OD}_{\text {medium }}$ represented the values of $\mathrm{OD}_{450 \mathrm{~nm}}$ of wells of $\mathrm{SiO}_{2}$-treated cells, medium containing $\mathrm{SiO}_{2}$, untreated control cell culture, and blank medium alone, respectively. All experiments were performed with biological triplicates, and data were representative of at least three independent experiments.

2.5. Western Blotting Analysis. The total protein of cells was extracted from cells treated with $100 \mu \mathrm{g} / \mathrm{cm}^{2}$ of $\mathrm{SiO}_{2}$ for $48 \mathrm{~h}$ using cell lysis buffer (Kaiji Biotech Ltd., Beijing, China). The nuclear protein was extracted with a NE-PER ${ }^{\mathrm{TM}}$ Nuclear Extraction kit (Thermo Fisher Scientific China, Shanghai, China). The total protein of the mouse lung was isolated by homogenizing the tissue in Enhanced RIPA Lysis Buffer (Leagene Biotech Ltd., Beijing, China), followed by centrifugation. The cell lysate or homogenized lung tissue was then centrifuged at $12,000 \times \mathrm{rpm}$ for $20 \mathrm{~min}$ at $4^{\circ} \mathrm{C}$; the superna- tants were collected as total proteins. The concentration of protein was detected using the BCA Protein Assay Kit (Kaiji Biotech Ltd., Beijing, China). The proteins $(30 \mu \mathrm{g})$ were resolved by $8 \%-10 \%$ sodium dodecyl sulfate- (SDS-) polyacrylamide gel (SDS-PAGE) and transferred to a PVDF membrane (Millipore, Billerica, MA, USA). The membrane was then blocked in 5\% nonfat milk in TBS for 1 hour at room temperature (RT). The protein of interest was probed with its specific antibodies, and the blots were then developed using the enhanced chemiluminescence (ECL) reagent (Amersham Biosciences, Piscataway, NJ, USA) as described elsewhere. The levels of protein expression were semiquantified by optical densitometry using ImageJ Software version 2.0.0 (http://rsb.info.nih.gov/ij/). The ratio between the net intensity of each sample divided by the GAPDH internal control was calculated as a densitometric arbitrary unit (A.U.), which served as an index of the relative expression of the protein of interest. The use and information of primary antibodies employed in the present study are listed in Suppl. Tables S1 and S2.

2.6. Histological and Immunofluorescent Staining. In order to histologically examine the pathology of the lungs of mice exposed to silica, the lung tissue of mice was fixed in $10 \%$ neutral formalin and processed paraffin embedding and section for pathohistological analysis by hematoxylin and eosin (HE) staining. Meanwhile, a part of the lung tissue was fixed in $4 \%$ paraformaldehyde (PFA) in PBS for 2 days prior to being embedded in an Optimal Cutting Temperature (OCT) compound for immunofluorescence (IF) staining on $10 \mu \mathrm{m}$ frozen tissue sections. For IF staining cells on coverslips, cells were seeded in the Glass Bottom Cell Culture Dish (diameter of $15 \mathrm{~mm}$ ) at a density of $5 \times 10^{4}$ cells/dish and cultured overnight prior to exposure to silica dust $\left(100 \mu \mathrm{g} / \mathrm{cm}^{2}\right)$ for an additional $24 \mathrm{~h}$ or $48 \mathrm{~h}$. Then, the cells were fixed with $4 \%$ PFA for $15 \mathrm{~min}$. For IF staining, the 4\% PFA-fixed slides were permeabilized by $0.2 \%$ TritonX-100/PBS for $20 \mathrm{~min}$ at $\mathrm{RT}$, followed by being blocked with $5 \%$ normal donkey serum in PBS for $1 \mathrm{~h}$ at RT. The appropriately diluted primary antibody to the protein of interest was then applied to the section and incubated at $4^{\circ} \mathrm{C}$ overnight. The binding of primary antibody was detected by Alexa Flour fluorescence (488 or 565)-conjugated secondary antibodies. The EdU corporation assay was performed using the Click-iT ${ }^{\mathrm{TM}}$ EdU Cell Proliferation Kit as per the manufacturer's instruction (Cat\# C10340, Thermo Fisher Scientific China, Shanghai, China). The slides were mounted with VectShield with DAPI medium (H-1200, Vector Laboratories, Burlingame, CA) for visualizing and imaging using a Leica TCS SP2 A0BS Confocal System and processed on Leica Confocal Software v.2.6.1 (Leica, Germany).

2.7. Flow Cytometry Analysis of ROS. Cells $\left(1 \times 10^{5}\right.$ cells/well $)$ cultured in a 6-well plate were infected with adenoviral vector for $24 \mathrm{~h}$ and/or treated with or without silica for an additional $48 \mathrm{~h}$ before the intercellular ROS was assessed by a flow cytometry assay. Briefly, the cells were dissociated from the plate and washed with 1x PBS, followed by being incubated with the CellROX ${ }^{\circledR}$ Orange Reagent (CellROX ${ }^{\circledR}$ Oxidative 
Stress Reagents, C10443, Invitrogen) at a final concentration of $5 \mu \mathrm{M}$ that was prediluted in phenol red-free DMEM in the dark at $37^{\circ} \mathrm{C}$ for $30 \mathrm{~min}$. After the incubation, the CellROX ${ }^{\circledR}$ Orange Reagent solution was removed, and the removed medium and the cells were washed with PBS three times prior to being resuspended in PBS for flow cytometry analysis on a BD FACSCanto II. At least 10,000 events were analyzed for each condition. For ROS staining, cells were incubated with a $5 \mathrm{mmol} / \mathrm{L}$ CellROX ${ }^{\circledR}$ Orange Reagent in the dark at RT for $30 \mathrm{~min}$, before they were imaged under fluorescence microscopy. All experiments were performed with biological triplicates, and data are representative of at least three independent experiments.

2.8. Measurement of Reduced Glutathione (GSH). Cells were rinsed with PBS and lysed with $1 \%$ TritonX-100 in PBS for $30 \mathrm{~min}$ at $4^{\circ} \mathrm{C}$. The lysis was collected and centrifuged at $3500 \mathrm{rpm}$ for $10 \mathrm{~min}$. The supernatant was harvested for analysis. A total of $100 \mu \mathrm{L}$ supernatant was employed to measure the value of $\mathrm{OD}_{405} \mathrm{~nm}$ using the GSH Assay kit per the manual provided by the manufacturer (Jiancheng Institute of Biotechnology, Nanjing, China). The reduced GSH were normalized by protein concentrations. All experiments were performed with biological triplicates, and data are representative of at least three independent experiments.

2.9. Wnt/TCF Signaling Dual Luciferase Reporter Assay. The Wnt signaling TCF Reporter Plasmid (TopFlash) was a product of Millipore (Burlington, MA, USA), and the pCMVrenilla luciferase plasmid was purchased from Promega (Madison, WI, USA). In order to access the Wnt/ $\beta$-catenin activity, BEAS-2B cells cultured in 12-well plates were cotransfected with TCF Reporter Plasmid (TopFlash) and pCMV-renilla luciferase plasmid (for internal control for normalization of transfection efficiency) at a ratio of $50: 1$ using X-tremeGENE HP (Roche, Penzburg, Germany). The cells were exposed to silica dust $(2.0 \mathrm{~nm}$ size $)$ at $24 \mathrm{~h}$ post the transfection and continued to culture for an additional $24 \mathrm{~h}$ or $48 \mathrm{~h}$ before they were harvested for analysis. The cells were lysed in 1x Passive Reporter Lysis Buffer (Promega). Protein concentrations were determined using the Bradford method, and all lysates were normalized to the same protein concentration using the lysis buffer. Two microliters of normalized cell lysate was used for measurement of the relative luciferase activity units (RLU), for both firefly and renilla luciferase, using the dual luciferase assay kit (Promega). Transfection efficiencies were normalized by dividing the relative firefly luciferase units by the relative renilla luciferase units. Following normalization, values were represented as RLU. All experiments were performed with biological triplicates, and data are representative of at least three independent experiments.

2.10. Statistical Analysis. All of the experiments were performed for at least three biological repeats. Data are presented as the mean \pm standard error of the mean (SEM). All analyses were assessed using GraphPad Prism version 5 software (version 5.0, GraphPad Software Inc., La Jolla, CA, USA). Statistical significance was defined as $p<0.05$.

\section{Results}

3.1. An Enhanced Wnt/ $\beta$-Catenin Signaling Activity and Robust Expression NOX4 in Lungs of $\mathrm{SiO}_{2}$-Induced Silicosis Mice. In order to understand the potential roles of Wnt/beta-catenin signaling and NOX4 in the development and progression of a silicotic lung, the expression of several key components of $\mathrm{Wnt} / \beta$-catenin signaling cascade and NOX 4 protein and the fibrotic and fibrogenic factors in the lungs of $\mathrm{SiO}_{2}$-induced silicosis mice were ascertained by immunoblotting (IB) and immunofluorescent staining (IF) assays. The mice that intratracheally received silica dust exhibited abundant silicosis nodules in the parenchyma of lungs as evaluated by HE histological staining (Figures 1(a)-1(c)). Such silicosis nodule was not observed in lungs of control mice challenged with saline (Figures $1(\mathrm{~d})-1(\mathrm{f})$ ). Of note, no difference in the pathogenesis of silicosis between male and female mice was observed. Molecular analysis using an immunoblotting assay uncovered that the NOX4 and Wnt/ $\beta$-catenin signaling were elevated in silica-challenged lungs as accessed by an increased abundance of NOX4, active $\beta$-catenin $(\mathrm{ABC})$, and Axin2 but decreased Wnt inhibitor DKK1 protein (Figures $1(\mathrm{~g})$ and $1(\mathrm{~h})$ ). The enhanced activity of NOX4 and Wnt signaling was accompanied by an increased production of profibrogenic proteins alpha smooth muscle actin ( $\alpha$-SMA) and vimentin, in lungs exposed to silica (Figures $1(\mathrm{~g})$ and $1(\mathrm{~h})$ ). Moreover, the increased abundances of Wnt3a, NOX4, $\alpha$-SMA, and vimentin were further corroborated to be predominantly expressed in the silicosis nodules of silica-challenged lungs as determined by the immunofluorescent staining (IF) assay (Figure 1(i)). These results evidenced an involvement of NOX4 and Wnt/ $\beta$-catenin signaling in the pathogenesis of the silicosis mouse lung.

3.2. $\mathrm{SiO}_{2}$ Activates Wnt/ $\beta$-Catenin Signaling and Augments NOX4 in Lung Epithelial Cells. Since the epithelialmesenchymal transition (EMT) or myofibrogenesis of lung epithelial cells is a hallmark of pulmonary fibrosis, a feature of silicosis [30], the alteration of $\mathrm{Wnt} / \beta$-catenin signaling activity and NOX4 expression of BEAS-2B lung epithelial cells in response to silica dust was examined. The cell viability assay suggested a $50 \%$ decrease of cell viability in lung epithelial BEAS-2B cells exposed to $200 \mu \mathrm{g} / \mathrm{cm}^{2}$ of $\mathrm{SiO}_{2}$ and revealed a dose-dependent inhibition of cell proliferation in cells exposed to $\mathrm{SiO}_{2}$ for $24 \mathrm{~h}$ and $48 \mathrm{~h}$ in a range of 0 $200 \mu \mathrm{g} / \mathrm{cm}^{2}$ (Figure 2(a)). As expected, the exposure of $\mathrm{SiO}_{2}$ $\left(100 \mu \mathrm{g} / \mathrm{cm}^{2}\right)$ led to a significantly enhanced activation of Wnt $/ \beta$-catenin signaling in BEAS-2B cells compared to the saline control $(p<0.01)$, as assessed by IF staining of Wnt3a ligand in the cytoplasm and ABC in nuclei (Figure 2(b)), the Wnt/Tcf-Lef transcriptional activity using a dual luciferase reporter assay, a readout of $\mathrm{Wnt} / \beta$-catenin signaling (Figure 2(c)), and immunoblotting (IB) assay (Figures 2(d) and $2(\mathrm{e}))$. The elevated Wnt activity was accompanied by an increased abundance of $\mathrm{Wnt} / \beta$-catenin signaling ligand Wnt3a and mediator nuclear active $\beta$-catenin (ABC), which was corroborated by the IF staining (Figure 2(b)) and IB assay (Figures 2(d) and 2(e)). 


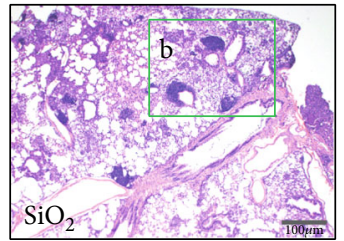

(a)

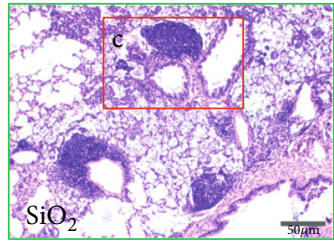

(b)

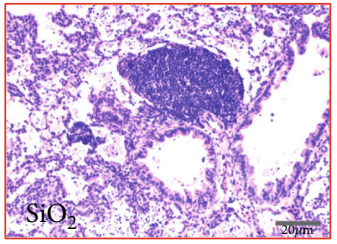

(c)

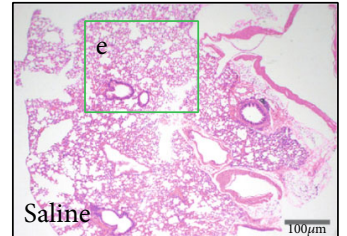

(d)

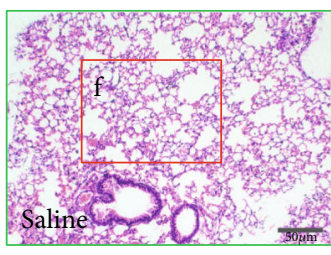

(e)

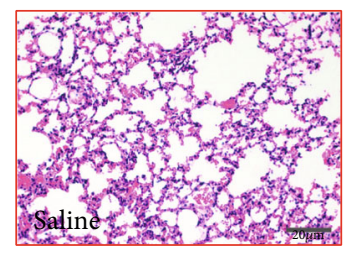

(f)

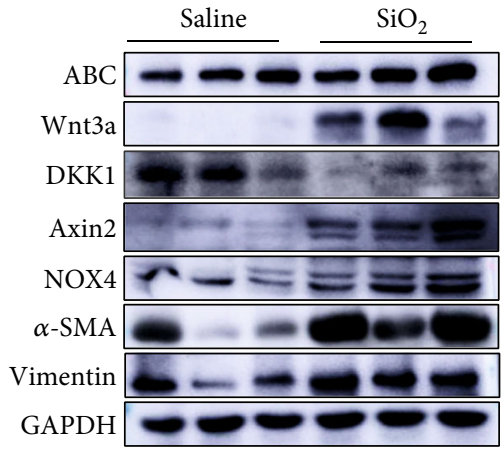

(g)

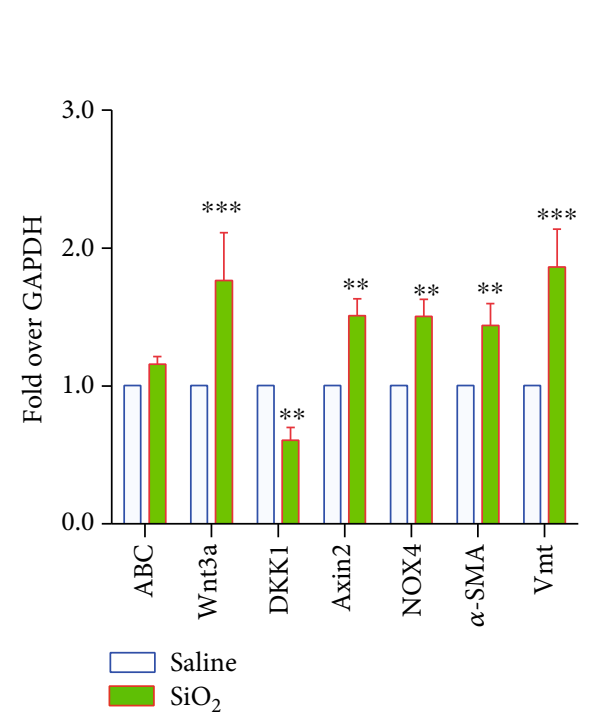

(h)
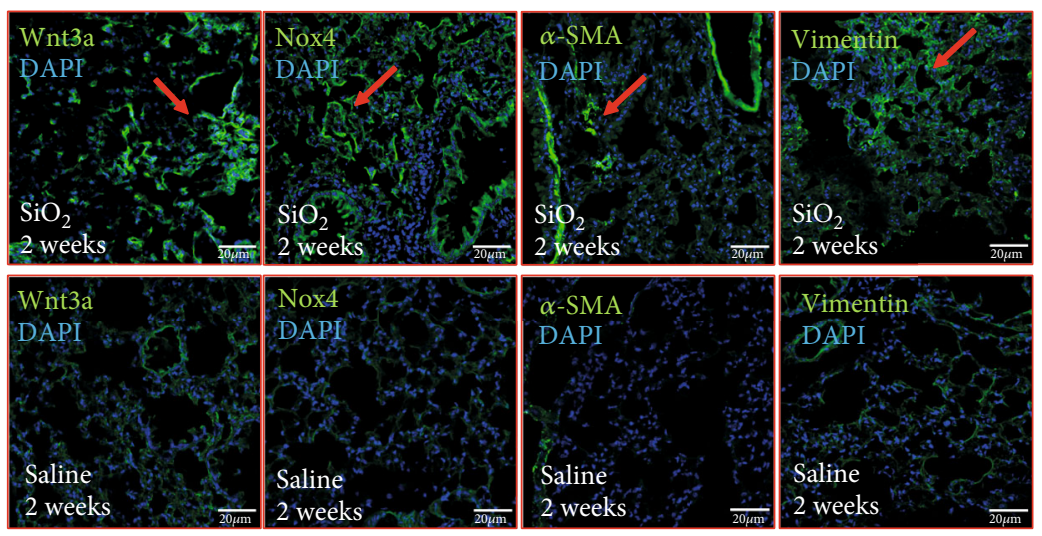

(i)

FIgURE 1: An elevated Wnt/ $\beta$-catenin signaling activity and expression of NOX4 in lungs of mice exposed to silica $\left(\mathrm{SiO}_{2}\right)$ dust. The lungs of C57BL/6 mice were harvested at 2 weeks post the exposure of saline control or silica dust (sizes ranged $0.5-10 \mu \mathrm{m}$ ) for histological analysis by HE staining (a-f), examining alternations of the expression of signaling molecules by immunoblotting assay (g) and immunofluorescent staining (h). (a-f) Representative images of lungs of mice exposed to saline control $(a-c)$ and silica dust (d-f). Abundant silicosis nodules were observed in lungs of mice challenged with silica dust $(a-c)$, but not in the saline control group (d-f). (B, C, E, and F) Frame insets depict the regions of corresponding images shown in (b, c, e, f). (g) Immunoblotting analysis demonstrated an increased expression of NOX4 protein and an enhanced $\mathrm{Wnt} / \beta$-catenin signaling activity as accessed by the increased abundance of active $\beta$-catenin (ABC) and Axin2 but a decreased Wnt inhibitor DKK1, accompanied by increased deposition of profibrogenic epithelial-mesenchymal transition (EMT) proteins alpha smooth muscle actin ( $\alpha$-SMA) and vimentin, in lungs exposed to silica. (h) Semiquantitative analysis of the expression of indicated proteins in ( $\mathrm{g}$ ) by evaluating the relative densitometric densities. (i) The increased expression of Wnt/ $\beta$-catenin signaling ligand Wnt3a, NOX4, $\alpha$-SMA, and vimentin was also predominantly detected in the silicosis nodules of silica-challenged lungs (top panel), compared to the saline (bottom panel) as ascertained by immunofluorescent staining (IF). DAPI was used for nuclear staining. Vmt: vimentin in (h). Bars in (a,d) $100 \mu \mathrm{m}$; (b, e) $40 \mu \mathrm{m}$; (c, f) $20 \mu \mathrm{m}$; (i) $50 \mu \mathrm{m}$. Data in (h) represented the mean \pm SEM of 9 mice from 3 independent experiments. Compared to the control group, ${ }^{*} p<0.05,{ }^{* *} p<0.01$, and ${ }^{* * *} p<0.001$.

In order to examine the potential of $\mathrm{SiO}_{2}$ in the induction of ROS production and EMT of epithelial cells, we examined the expression of NOX proteins and EMT-related molecules in cells exposed to silica for both $24 \mathrm{~h}$ and $48 \mathrm{~h}$, although a significant reduction of cell viability was induced by the exposure of $\mathrm{SiO}_{2}$ at $100 \mu \mathrm{g} / \mathrm{cm}^{2}$ for $48 \mathrm{~h}$. As expected, a dose-dependent increase of ROS production was observed in BEAS-2B cells treated with $\mathrm{SiO}_{2}$ for $48 \mathrm{~h}$, but not $24 \mathrm{~h}$ post 


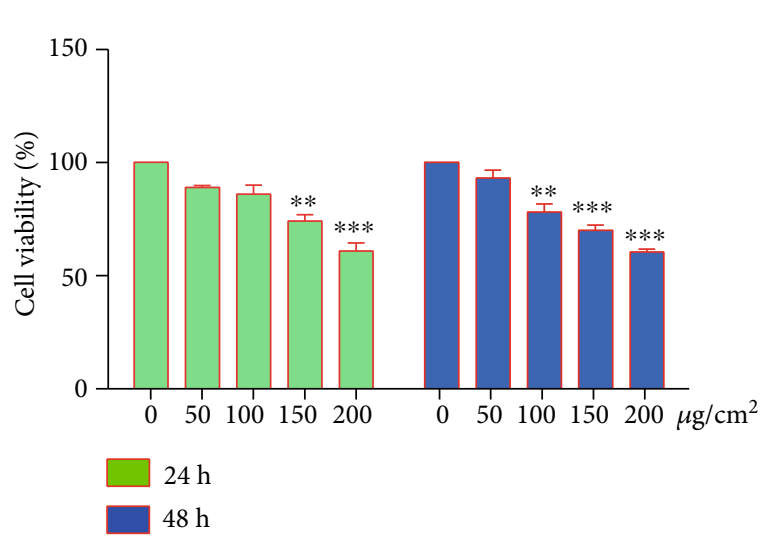

(a)

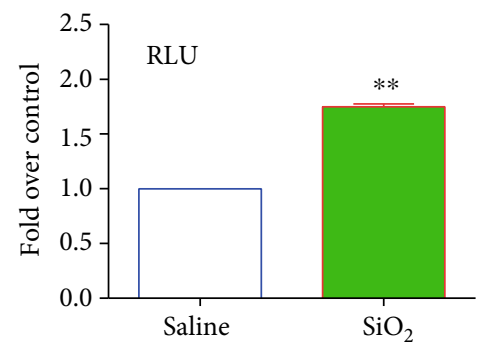

(c)

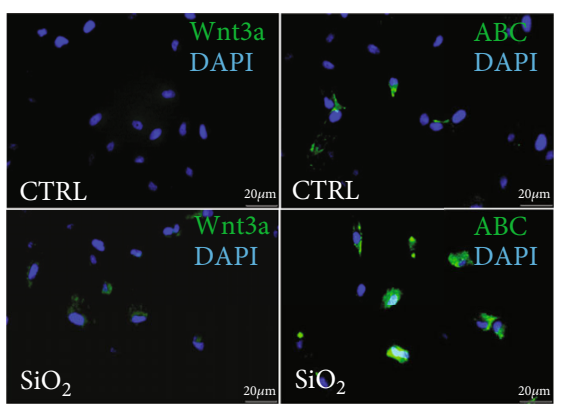

(b)

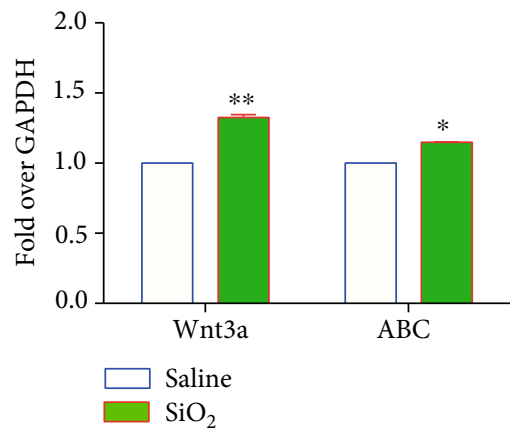

(e)

FIgURE 2: $\mathrm{SiO}_{2}$ activates $\mathrm{Wnt} / \beta$-catenin signaling in lung epithelial BEAS-2B cells. The lung epithelial BEAS-2B cells were exposed to different doses of $\mathrm{SiO}_{2}(2 \mathrm{~nm}$ in size) for $24 \mathrm{~h}$ or $48 \mathrm{~h}$, the cell viability (a) and Wnt/ $\beta$-catenin signaling activity were examined. (a) A dose-dependent inhibition of cell viability was observed in BEAS-2B cells exposed to $\mathrm{SiO}_{2}$ for $24 \mathrm{~h}$ and $48 \mathrm{~h}$ as determined by a CCK8 assay. (b) Immunofluorescent staining further corroborated the increased expression of Wnt3a and active $\beta$-catenin (ABC) proteins in cells treated with $100 \mu \mathrm{g} / \mathrm{cm}^{2}$ of $\mathrm{SiO}_{2}$ for $48 \mathrm{~h}$ in comparison with the saline control. (c) Dual luciferase reporter assay demonstrated a significantly enhanced $\mathrm{SiO}_{2}$-activated $\mathrm{Wnt} / \beta$-catenin signaling in BEAS-2B cells exposed to $100 \mu \mathrm{g} / \mathrm{cm}^{2}$ of $\mathrm{SiO}_{2}$ for $48 \mathrm{~h}$ compared with the saline control (CTRL) $(p<0.01)$. (d) Immunoblotting assay also revealed an increased abundance of Wnt3a and ABC in BEAS-2B cells exposed to $100 \mu \mathrm{g} / \mathrm{cm}^{2}$ of $\mathrm{SiO}_{2}$ for $48 \mathrm{~h}$ relative to that of CTRL. (e) Semiquantitative analysis of the expression of indicated proteins in (d) by evaluating the relative densitometric densities. Bars in (b) $20 \mu \mathrm{m}$. Compared to the CTRL, ${ }^{*} p<0.05$ and ${ }^{* *} p<0.01$.

the exposure of silica dust relative to the saline (Figure 3(a)), suggesting inhibition of cell proliferation in cells exposed to $\mathrm{SiO}_{2}$. As NOX proteins were the major source of intracellular ROS [31], alterations of several NOX family proteins were examined in BEAS-2B cells upon $\mathrm{SiO}_{2}$ stimulation. Indeed, the increase of ROS production was along with an increased abundance of NOX 4 and profibrogenic factors $\alpha$-SMA and a reduction of E-cadherin protein (Figures 3(b)-3(d)). Of note, $\mathrm{SiO}_{2}$ failed to induce the expression of NOX1 and NOX5 as determined by the IB assay (Figures 3(b) and 3(c)). The $\mathrm{SiO}_{2}$-induced expression of NOX4 and $\alpha$-SMA and another profibrogenic protein vimentin was further validated by IF in BEAS-2B cells (Figure 3(e)).

Intriguingly, the ROS scavenger $\mathrm{N}$-acetyl-L-cysteine (NAC) $(10 \mathrm{mmol} / \mathrm{L})$ exhibited a capacity to diminish $\mathrm{SiO}_{2}{ }^{-}$ activated $\mathrm{Wnt} / \beta$-catenin signaling as determined by the altered abundance of nuclear $\mathrm{ABC}$ protein, although no significant change of nuclear $\mathrm{ABC}$ was detected in cells treated with NAC alone (Figure 4(a) ). Notably, the NAC treatment also displayed the ability to reduce $\mathrm{SiO}_{2}$-induced EMT and fibrogenic proteins MMP2, $\alpha$-SMA, and vimentin and EMT suppressor E-cadherin, despite the fact that $\mathrm{SiO}_{2}$ or $\mathrm{NAC}$ alone failed to significantly alter the expression of these proteins in BEAS-2B cells (Figure 4). Of note, in addition to the inhibition of cell proliferation, the exposure of $\mathrm{SiO}_{2}$ also induced cell apoptosis as determined by an increased expression of caspase-3-mediated proapoptotic proteins including cleaved caspase- 3 and BAX, but a reduced expression of antiapoptotic protein relative to the saline control (Figures 4(a) and $4(\mathrm{~d})$ ). The presence of NAC could reduce the expression of $\mathrm{SiO}_{2}$-induced apoptotic proteins (Figures $4(\mathrm{a})$ and $4(\mathrm{~d})$ ), suggesting that the exposure of silica could inhibit cell proliferation and induce cell apoptosis in BEAS-2B cells. Together, these data suggested that the $\mathrm{SiO}_{2}$-induced NOX4 and ROS generation played a pivotal role in the EMT and fibrogenesis in lung epithelial cells during silicosis, which also implied an underlying mechanism by which interaction between the Wnt/ $\beta$-catenin signaling and NOX4 of lung epithelial cells was implicated in the pathogenesis of silicosis lungs.

3.3. Wnt/ $\beta$-Catenin Signaling Alters NOX4-Mediated ROS Production in Lung Epithelial Cells. In order to investigate 


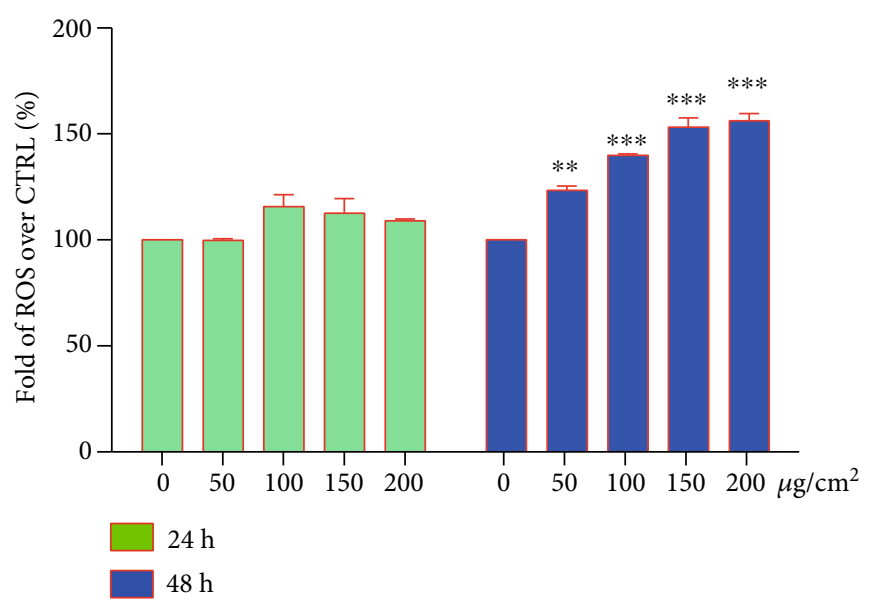

(a)

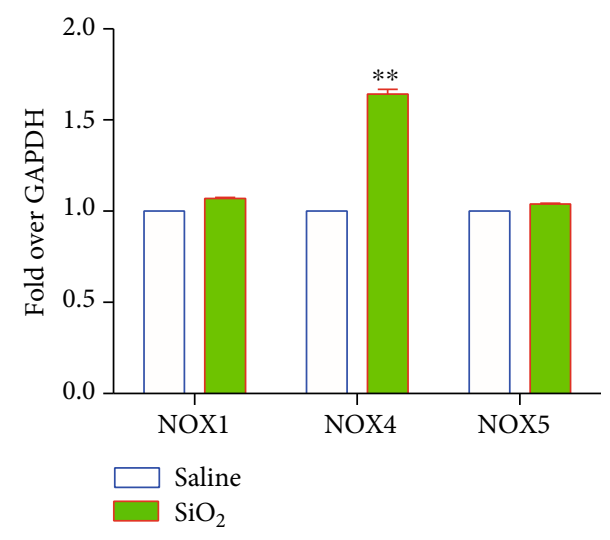

(c)
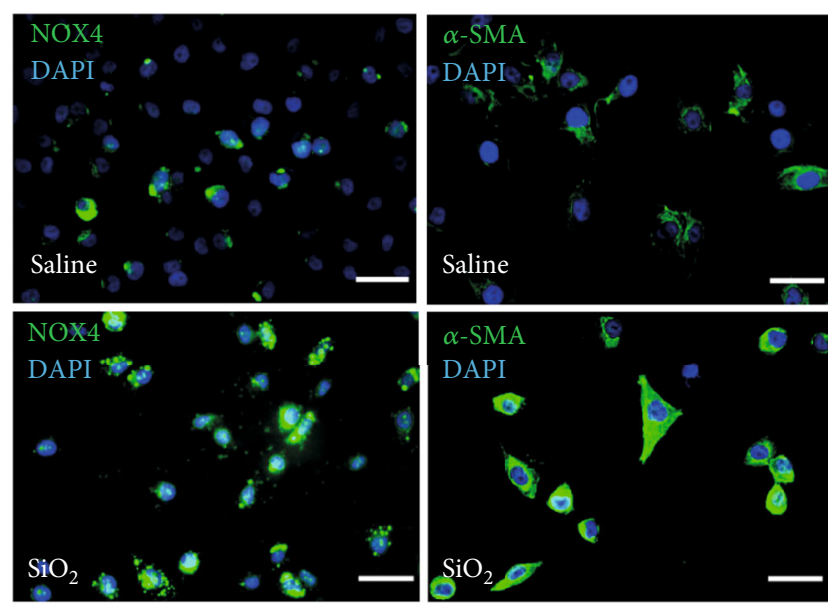

(e)

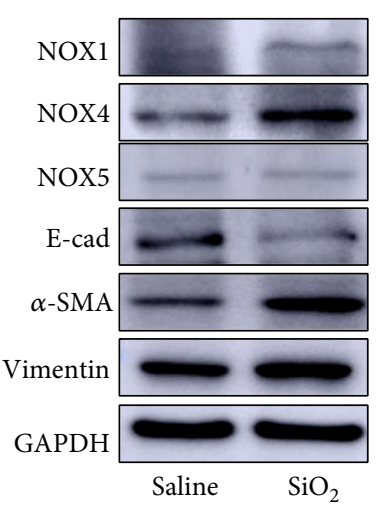

(b)

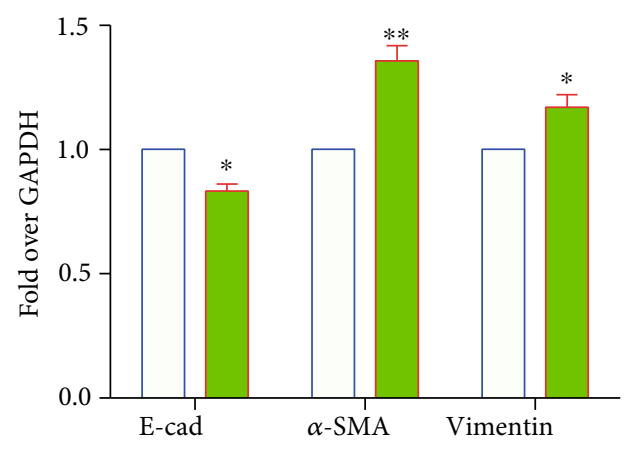

(d)

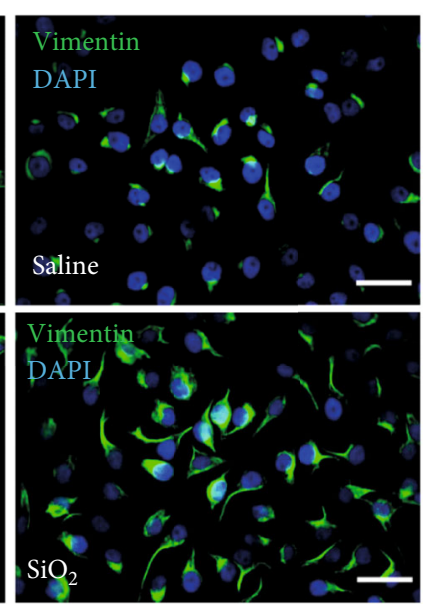

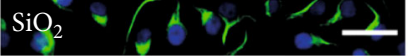

FIgURE 3: $\mathrm{SiO}_{2}$ alters the NOX-mediated ROS production and promotes EMT and cell apoptosis in lung epithelial BEAS-2B cells. The lung epithelial BEAS-2B cells were exposed to different doses of $\mathrm{SiO}_{2}(2 \mathrm{~nm}$ in size) for $24 \mathrm{~h}$ or $48 \mathrm{~h}$; the alteration of ROS production (a) and

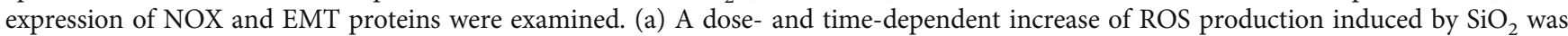
determined in BEAS-2B cells at $48 \mathrm{~h}$ but not $24 \mathrm{~h}$ post exposure to silica dust. (b) Immunoblotting assay revealed an increased expression of NOX4 and $\alpha$-SMA but reduced expression of E-cadherin in BEAS-2B cells exposed to $100 \mu \mathrm{g} / \mathrm{cm}^{2}$ of $\mathrm{SiO}_{2}$ for $48 \mathrm{~h}$ relative to the saline. (c) Semiquantitative analysis of the expression of NOX1, NOX4, and NOX5 proteins in (b) by evaluating the relative densitometric densities. (d) Semiquantitative analysis of the expression of EMT-related proteins E-cadherin, $\alpha$-SMA, and vimentin in (b) by evaluating the relative densitometric densities. (e) Representative images of IF exhibited more abundant NOX4, $\alpha$-SMA, and vimentin proteins in BEAS-2B cells exposed to $100 \mu \mathrm{g} / \mathrm{cm}^{2}$ of $\mathrm{SiO}_{2}$ for $48 \mathrm{~h}$ as compared with the saline control. Bars in (c) $20 \mu \mathrm{m}$. Compared to the CTRL, ${ }^{* *} p<0.01 ;{ }^{* * *} p<0.001$. 

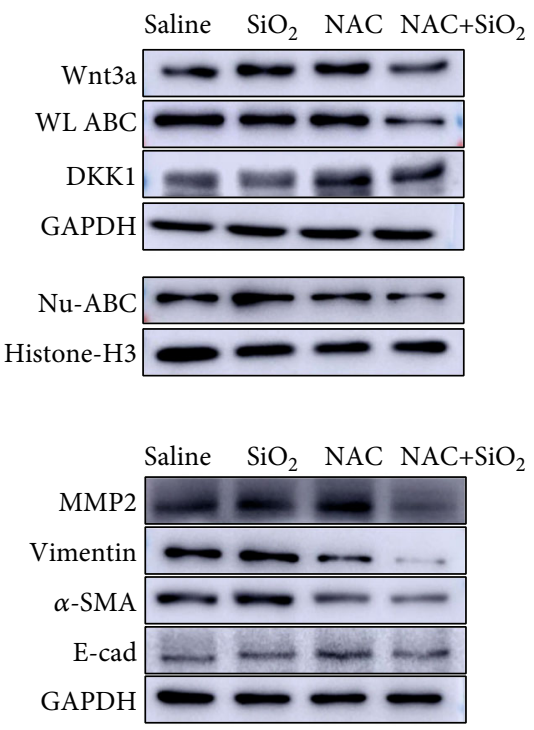

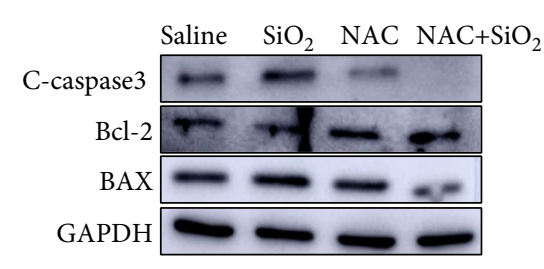

(a)

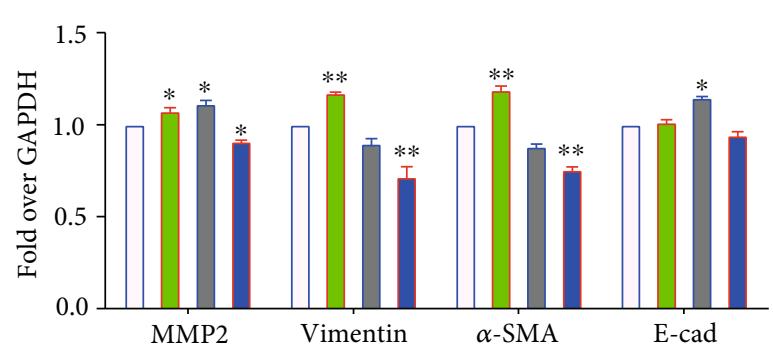

(c)

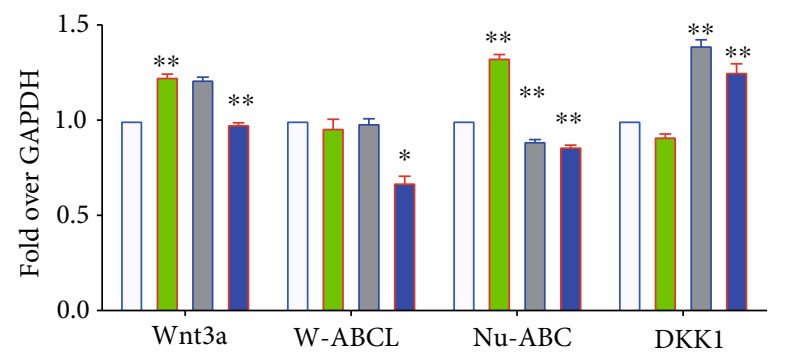

(b)

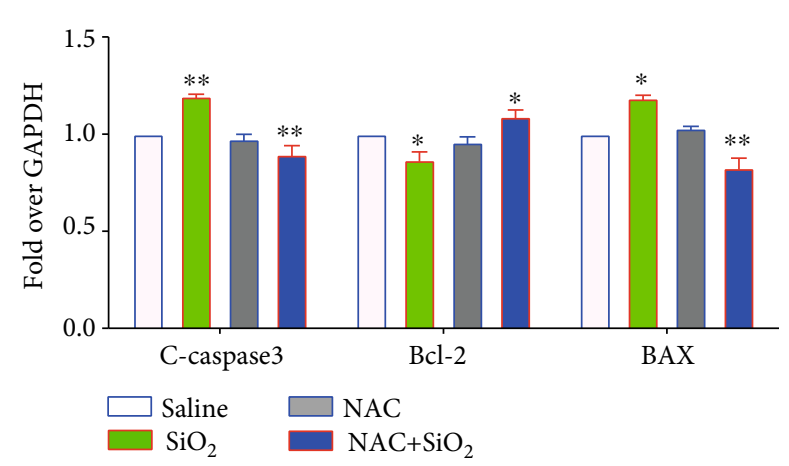

(d)

FIgure 4: ROS scavenger NAC inhibits $\mathrm{SiO}_{2}$-induced Wnt/ $\beta$-catenin signaling activity and expression of fibrogenic factors. The lung epithelial BEAS-2B cells were exposed to $100 \mu \mathrm{g} / \mathrm{cm}^{2}$ of $\mathrm{SiO}_{2}(2 \mu \mathrm{m}$ in size $)$ for $48 \mathrm{~h}$ in the presence or absence of ROS scavenger NAC; the abundance of the indicated Wnt/ $\beta$-catenin signaling key molecules, fibrogenic factors, and signaling of caspase-3-mediated cell apoptosis were examined by an immunoblotting assay. (a) Representative immunoblots showed that the presence of $\mathrm{NAC}$ reduced the $\mathrm{SiO}{ }_{2}$-induced $\mathrm{Wnt} / \beta$-catenin signaling ligand Wnt3a and mediator nuclear ABC but increased the expression of Wnt inhibitor DKK1 (top panel); suppressed the $\mathrm{SiO}_{2}$-induced fibrogenic factors MMP2, vimentin, and $\alpha$-SMA but increased the abundance of epithelial cell marker Ecadherin (middle panel); and decreased the $\mathrm{SiO}_{2}$-induced abundance of cleaved caspase- 3 and BAX but increased the expression of antiapoptotic protein Bcl-2 in BEAS-2B cells exposed to $100 \mu \mathrm{g} / \mathrm{cm}^{2}$ of $\mathrm{SiO}_{2}$ for $24 \mathrm{~h}$ relative to the saline control (bottom panel). (b) Semiquantitative analysis of the expression of Wnt signaling proteins Wnt3a, ABC, and DKK1 in (a) by evaluating the relative densitometric densities using arbitrary units (A.U.). (c) Semiquantitative analysis of the expression of fibrogenic factors MMP2, vimentin, $\alpha$-SMA, and E-cadherin in (a) by evaluating the relative densitometric densities using arbitrary units (A.U.). (d) Semiquantitative analysis of the expression of apoptotic marker cleaved caspase-3 and BAX and antiapoptotic protein Bcl-2 in (a) by evaluating the relative densitometric densities using arbitrary units (A.U.). Data were expressed as the mean \pm SEM from three independent experiments. Compared to the CTRL, ${ }^{* *} p<0.01 ;{ }^{* * *} p<0.001$. WL-ABC: whole cell lysate active beta-catenin; Nu-ABC: nuclear active beta-catenin.

the interaction between the $\mathrm{Wnt} / \beta$-catenin signaling and NOX4 in lung epithelial cells, the signaling activity was altered in BEAS-2B cells by the infection of adenoviral vector expressing mouse Wnt3a (AdWnt3a) or DKK1 (AdDKK1), and the change of ROS production in response to $\mathrm{SiO}_{2}$ exposure was measured. The IB assay showed a robust expression 
of Wnt3a and DKK1 proteins in cells infected with AdWnt3a and AdDKK1, along with an increase and decrease of ABC protein in comparison to cells infected by control AdC vector, respectively (Figures 5(a) and 5(b)). Notably, the AdWnt3a-mediated activation of $\mathrm{Wnt} / \beta$-catenin signaling resulted in an increased $\alpha$-SMA and vimentin proteins, but a reduced E-cadherin (Figures 5(a) and 5(c)). Of note, the Wnt3a or DKK1 alone was able to alter the NOX4 expression and ROS productions in BEAS-2B cells, regardless of the exposure of $\mathrm{SiO}_{2}$ (Figures 5(a)-5(e) ), despite the fact that $\mathrm{SiO}_{2}$ alone also significantly induced ROS generation, as demonstrated by both the fluorescent staining with CellROX $^{\circledR}$ Orange Reagent (Figure 5(d)) and FACS quantitative assay (Figure 5(e)). In addition, the activated Wnt signaling also inhibited the production of reduced glutathione (GSH) compared to AdC-infected cells (Figure 5(f)). As expected, the AdDKK1-mediated inhibition of $\mathrm{Wnt} / \beta$-catenin signaling led to an opposite effect to Wnt3a (Figure 5). These results suggested a mechanism by which the $\mathrm{SiO}_{2}$-activated Wnt/ $\beta$-catenin signaling induced NOX4 expression, which substantially increased the ROS production and the expression of EMT and fibrogenic proteins in lung epithelial cells.

3.4. NOX4 Enhances Wnt/ $\beta$-Catenin Signaling and Promotes EMT in Lung Epithelial Cells. Next, we sought to explore whether NOX4 was able to alter $\mathrm{Wnt} / \beta$-catenin signaling in lung epithelial cells in response to silica dust. To this end, the function of NOX4 in BEAS-2B cells was altered by infections of adenoviral vectors expressing NOX4 (AdNOX4) or short hairpin RNA (shRNA) to NOX4 gene (AdshRNA). As expected, an increased abundance of NOX4 protein was found in cells infected with AdNOX4, and a decreased NOX4 protein was detected in cells infected with AdshRNA, suggesting that these adenoviral vectors were capable of overexpressing and knocking down NOX4 in BEAS-2B cells (Figures 6(a) and 6(b)). Consequentially, the AdNOX4mediated overexpression of NOX 4 activated $\mathrm{Wnt} / \beta$-catenin signaling as determined by an increased abundance of Wnt3a, ABC, cyclin D1, and Axin2. The activation of $\mathrm{Wnt} / \beta$-catenin signaling was further corroborated by IF of ABC (Figure 6(c)), and the expression of NOX4 increased the EdU incorporation in BEAS-2 cells, implying that NOX4 was able to promote epithelial cell proliferation (Figure 6(c)). Of interest, the overexpression of NOX4 significantly inhibited DKK1 protein in BEAS-2 cells (Figures 6(a) and 6(b)). As seen in the above AdWnt3a-infected cells, the NOX4-activated Wnt/ $\beta$-catenin signaling also increased the expression of fibrogenic factors, and oxidative stress-related proteins NFE2-related factor 2 (Nrf2) in BEAS-2B cells, but the expression of Nfr2-regulated gene heme oxygenase-1 (HO-1) has not altered the ectopic expression of NOX4 (Figures 6(a) and 6(b)). In contrast to that seen in cells overexpressing NOX4, the expression of the above-examined proteins in cells with shRNA-mediated NOX4 knockdown was opposite (Figures 6(a)-6(c)). Consistent with the Wnt3a-mediated Wnt activation, the overexpression of NOX4 increased the ROS production (Figures 6(d) and $6(\mathrm{e})$ ), while suppressing the production of reduced glutathione (GSH) (Figure 6(f)), and a knockdown of NOX4 reduced
ROS production but induced GSH production in BEAS-2B cells regardless of $\mathrm{SiO}_{2}$ stimulation (Figures 6(d)-6(f)). These data suggested that the $\mathrm{SiO}_{2}$-induced $\mathrm{NOX} 4$ expression could enhance $\mathrm{Wnt} / \beta$-catenin signaling activity, which in turn increased ROS generation and reduced GSH, which ultimately induced cell injury and promoted the EMT in lung epithelial cells.

\section{Discussion}

Silicosis is characterized as a chronic fibrotic lung disease caused by repeated inhalation of excessive silica dust. The exposure of silica insults induces sustained inflammations and oxidative stress, resulting in a direct or indirect injury to the alveolar epithelium in distal lungs. In response to the injury, the epithelial cells are able to repair by initiating the injury/repair processes that are tightly regulated by interactions between varied cellular signaling pathways. However, dysregulation of these signaling may lead to the initiation of fibrotic response in pulmonary fibrosis [32]. Among these signaling, the Wnt signaling was linked with the development of fibrosis [9] and was altered by silica dust in lung epithelial cells in vitro and silicosis animal model in vivo, through mechanisms by which it interacted with other signaling or molecules and contributed to profibrogenic and inflammatory responses in lung epithelial cells $[13-15,33]$.

In the present study, the interaction between the Wnt/ $\beta$ catenin signaling and NOX4 in the proliferation and profibrogenic response to $\mathrm{SiO}_{2}$ in human epithelial cells was interrogated. The results demonstrated that both $\mathrm{Wnt} / \beta$ catenin and NOX4 signaling were elevated in the lungs of $\mathrm{SiO}_{2}$-induced silicosis mice. The exposure of $\mathrm{SiO}_{2}$ led to an inhibition of cell proliferation and induction of cell apoptosis, activation of $\mathrm{Wnt} / \beta$-catenin signaling, induction of the NOX4 and ROS production, and the expression of EMTrelated proteins in BEAS-2B human lung epithelial cells. Molecular analysis further revealed that the Wnt3amediated activation of $\mathrm{Wnt} / \beta$-catenin further increased the $\mathrm{SiO}_{2}$-induced NOX4 expression and ROS production but reduced GSH, while Wnt inhibitor DKK1 exhibited an opposite effect to Wnt3a. Vice versa, an ectopic expression of NOX4 enhanced the activity of Wnt/ $\beta$-catenin signaling and reduction of GSH, whereas the shRNA mediated knockdown of NOX4-enervated Wnt signaling activity and increase of GSH. Mechanistically, the NFE2-related factor 2 (Nrf2) antioxidant response was involved in the crosstalk between the $\mathrm{Wnt} / \beta$-catenin and NOX4 signaling in BEAS$2 \mathrm{~B}$ cells in response to $\mathrm{SiO}_{2}$ challenge.

Wnt signaling is pivotal to lung development and homeostatic maintenance of the mature lung, by mediating stem cell self-renewal, turnover, and injury/repair of epithelia [34, 35]. However, accumulating evidences have shown that Wnt has been implicated in many types of pulmonary diseases, and a dysregulated Wnt signaling in mature lungs was recognized as a driver that leads to excessive cell proliferation and improper cell differentiation for fibrotic repair [36, 37]. Indeed, a reactivated Wnt was identified as a key contributor in the initiation and development of hyperproliferative chronic pulmonary diseases $[9,12]$, such as idiopathic 


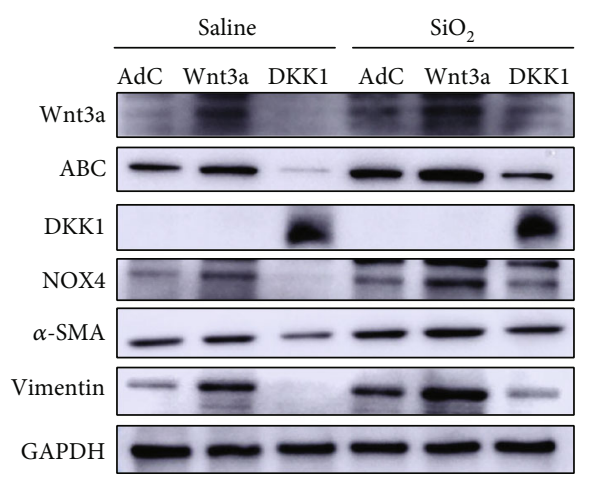

(a)

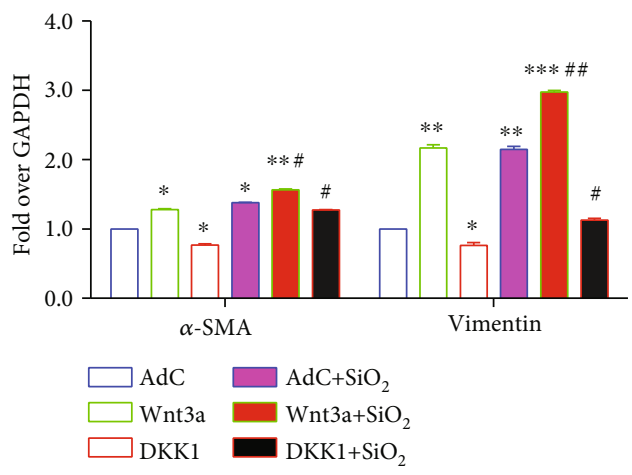

(c)

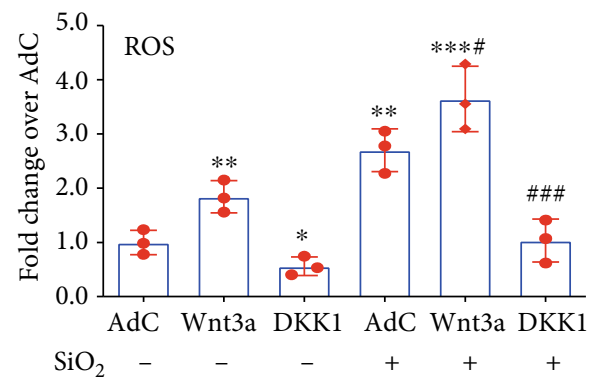

(e)

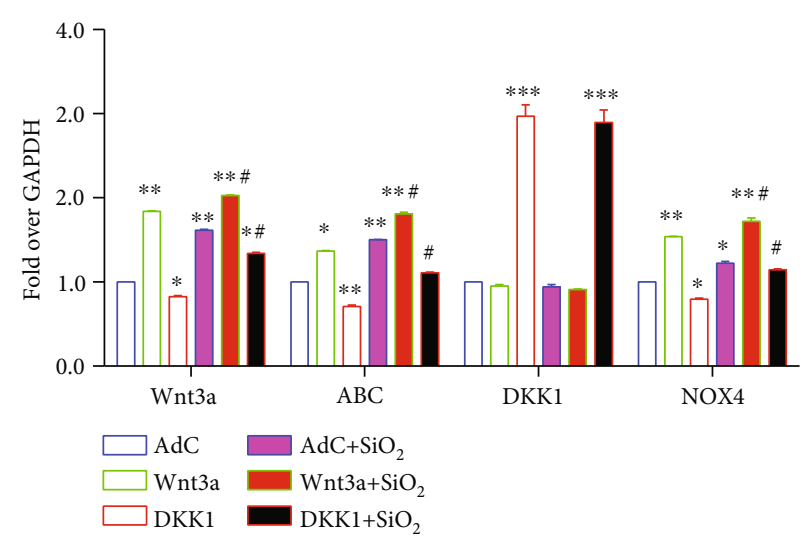

(b)

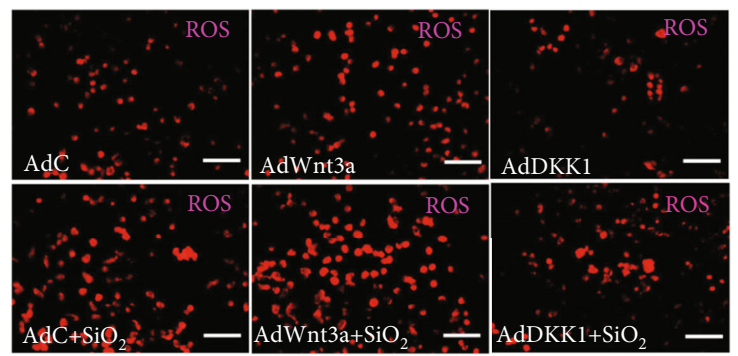

(d)

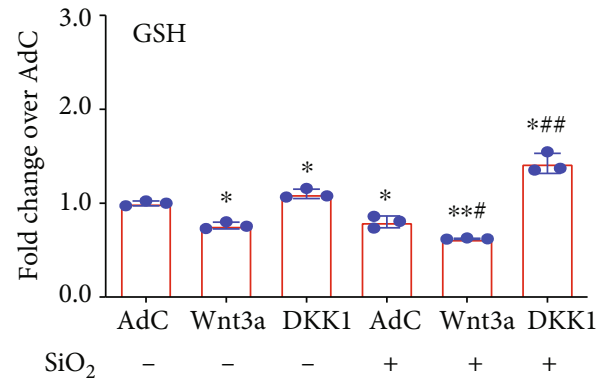

(f)

Figure 5: Impacts of $\mathrm{Wnt} / \beta$-catenin signaling on the expression of NOX4 and ROS production in lung epithelial cells in response to $\mathrm{SiO}_{2}$ exposure. The lung epithelial BEAS-2B cells were infected with adenoviral vectors at multiplicity of infection of 1000 for $24 \mathrm{~h}$ before they were exposed to $\mathrm{SiO}_{2}$ and cultured for additional $48 \mathrm{~h}$, the abundance of NOX4 and fibrogenic factors were examined by an immunoblotting assay $(\mathrm{a}-\mathrm{c})$, and production of ROS (d, e) and GSH (f) was determined by FACS and/or fluorescent staining. (a) Representative images of immunoblots of indicated proteins of interest showed the, respectively, increased and decreased expression of NOX4 and fibrogenic factors in cells infected with AdWnt3a and AdDKK1 regardless of $\mathrm{SiO}_{2}$ exposure, in comparison with cells infected by AdC control virus (CTRL). (b) Semiquantitative analysis of the expression of Wnt signaling proteins Wnt3a, ABC, DKK1, and NOX4 in (a) by evaluating the relative densitometric densities using arbitrary units (A.U.). (c) Semiquantitative analysis of the expression of fibrogenic factors $\alpha$-SMA and vimentin in (a) by evaluating the relative densitometric densities using arbitrary units (A.U.). (d) Representative images of cells treated with indicated conditions and stained with $5 \mathrm{mmol} / \mathrm{L}$ CellROX ${ }^{\circledR}$ Orange Reagent images displayed more robust ROS staining in cells exposed to $\mathrm{SiO}_{2}$ compared to cells without $\mathrm{SiO}_{2}$ exposure; a, respectively, increased and decreased intensive ROS staining was observed in AdWnt3a and AdDKK1-infected cells relative to AdC-infected cells. (e) Quantitative analysis showed that the Wnt3a-mediated activation of Wnt/ $\beta$-catenin signaling increased the ROS production in lung epithelial cells, regardless of the exposure to $\mathrm{SiO}_{2}$, and inhibition of the Wnt signaling by AdDKK1 infection dramatically reduced the ROS production, including the $\mathrm{SiO}_{2}$-induced ROS in these cells, as compared with the AdC-infected cell controls. (f) Effects of Wnt/ $\beta$-catenin signaling in the production of reduced glutathione (GSH) in lung epithelial cells. In addition to the reduction of $\mathrm{GSH}$ by $\mathrm{SiO}_{2}$, an activation of Wnt/ $\beta$-catenin signaling by Wnt3a further reduced the production of GSH, and the DKK1-mediated inhibition of Wnt signaling increased the GSH production in lung epithelial cells, regardless of the exposure to $\mathrm{SiO}_{2}$, as compared with the AdC-infected cells. Data are presented as the

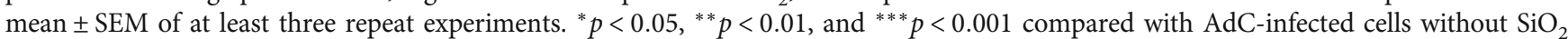
exposure; ${ }^{\#} p<0.05,{ }^{\# \#} p<0.01$, and ${ }^{\# \#} p<0.001$ compared to AdC-infected cells with $\mathrm{SiO}_{2}$ exposure. Bars in (d) $50 \mu \mathrm{m}$. 

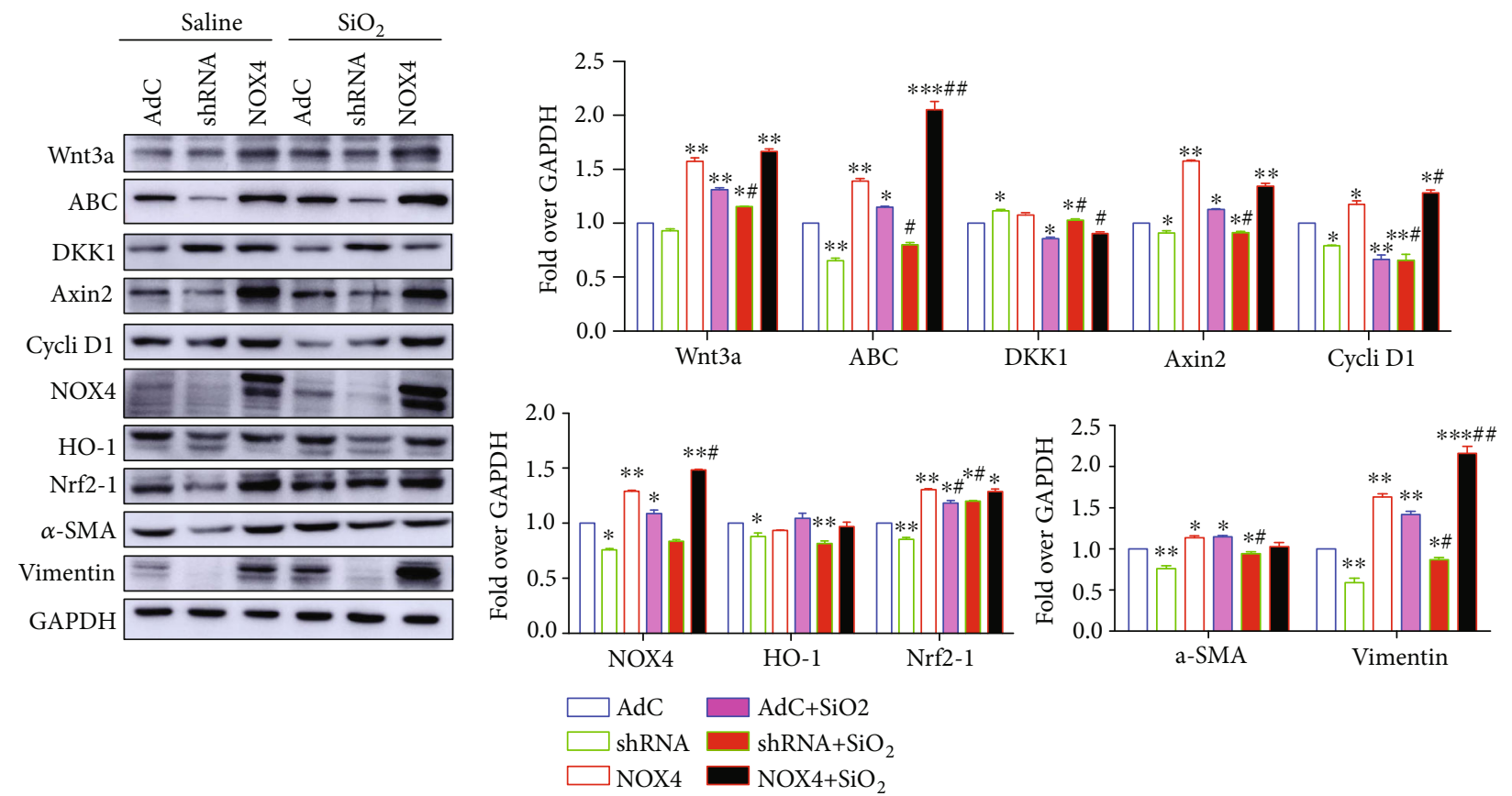

(a)

(b)

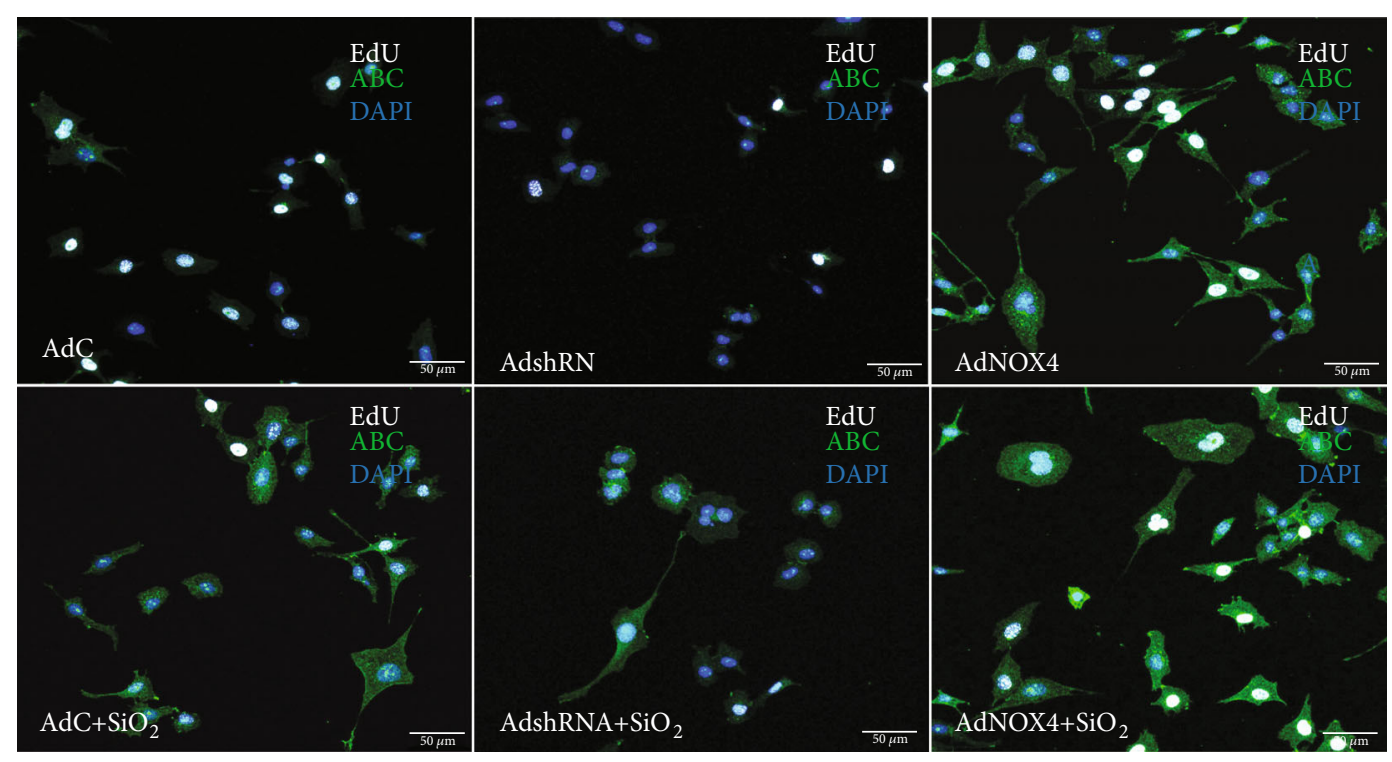

(c)

Figure 6: Continued. 


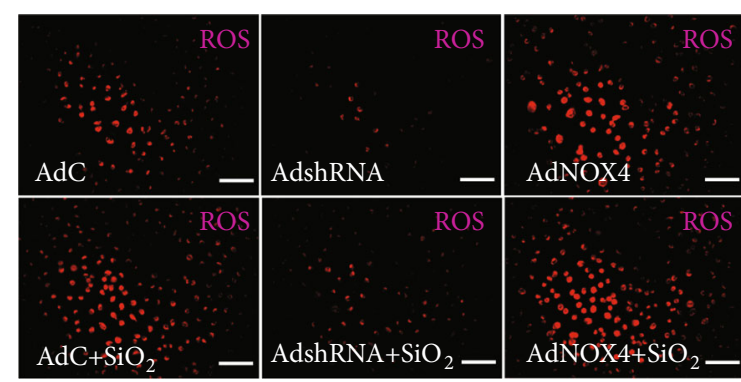

(d)

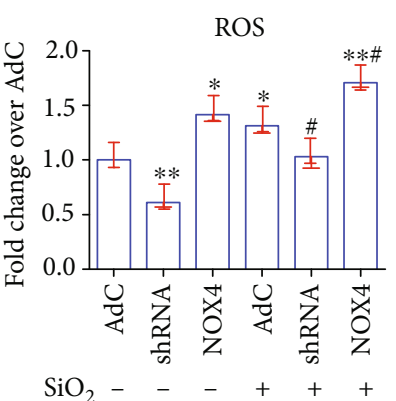

(e)

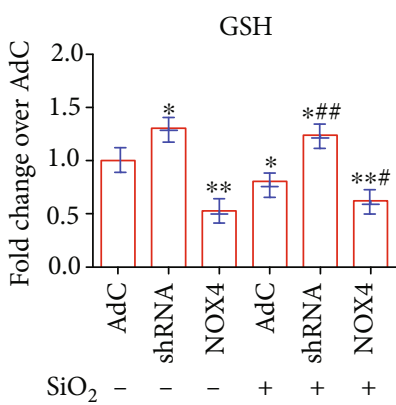

(f)

FIGURE 6: Effects of NOX4 on Wnt/ $\beta$-catenin signaling and EMT of lung epithelial cells in response to $\mathrm{SiO}_{2}$ exposure. The lung epithelial BEAS-2B cells were infected with indicated adenoviral vectors at multiplicity of infection of 1000 for $24 \mathrm{~h}$ before they were exposed to $\mathrm{SiO}_{2}$ and cultured for additional $48 \mathrm{~h}$; the expression of $\mathrm{Wnt} / \beta$-catenin signaling key molecules and fibrogenic factors (a, b) and the production of GSH (c) were examined. (a) Representative images of immunoblots of indicated proteins of interest. An overexpression of NOX4 in BEAS-2B cells resulted in an increased abundance of Wnt/ $\beta$-catenin signaling proteins Wnt3a, ABC, cyclin D1, and Axin2, but less abundant Wnt inhibitor DKK1, along with an increased expression of fibrogenic factors, and oxidative stress-related proteins HO-1 and Nrf-2. A shRNA-mediated knockdown of NOX4 led to an opposite effect of the overexpression of NOX4. (b) Semiquantitative analysis of the expression of proteins of Wnt signaling cassette (top panel), NOX4, HO-1, and Nrf-2 (bottom left panel) and fibrogenic factors (bottom right panel) in (a) by evaluating the relative densitometric densities using arbitrary units (A.U.). (c) Representative images of IF exhibited an activation of Wnt signaling mediated by NOX4 in BEAS-2B cells regardless of the exposure of $\mathrm{SiO}_{2}$ as ascertained by the expression of ABC and cell proliferation by EdU incorporation, while shRNA-mediated knockdown of NOX4 acted an opposite effect, as compared with the AdC control. (d) Representative images of ROS staining showed more robust ROS staining in cells infected with AdNOX4, while shRNA-mediated knockdown of NOX4 exhibited an opposite effect to AdNOX4, as compared with the saline and AdC controls. (e) Quantitative analysis showed the NOX4 further $\mathrm{SiO}_{2}$-induced increased the ROS production in lung epithelial cells infected with AdNOX4, while shRNA-mediated knockdown of NOX4 exhibited an opposite effect to AdNOX4, as compared with the saline and AdC controls. (f) Impacts of NOX4 in the production of reduced glutathione (GSH) in lung epithelial cells. The overexpression of NOX4 further reduced the production of GSH, and the shRNA-mediated suppression of NOX4 increased the GSH production in lung epithelial cells, as compared with the saline treatment and AdC-infected cells. Data are presented as the mean \pm SEM of at least three repeat experiments. ${ }^{*} p<0.05,{ }^{* *} p<0.01$, and ${ }^{* * *} p<0.001$ compared with AdC-infected cells without $\mathrm{SiO}_{2}$ exposure; ${ }^{\#} p<0.05$, ${ }^{\# \#} p<0.01$, and $\# \# p<0.001$ compared to AdC-infected cells with $\mathrm{SiO}_{2}$ exposure.

pulmonary fibrosis (IPF) [11, 38], asthma [39], and COPD [8, $11,34,40]$. With respect to silicosis, both $\beta$-catenin-mediated canonical signaling and $\beta$-catenin-independent noncanonical signaling were altered in human airway epithelial cells upon silica stimulation; the Wnt inhibitor SFRP1 and noncanonical ligand Wnt5a were downregulated, while another Wnt inhibitor DKK1 was upregulated [13], despite the fact that the canonical Wnt/ $\beta$-catenin signaling was reactivated in silicosis lungs $[14,15]$. Therefore, inhibition of $\mathrm{Wnt} / \beta$-catenin signaling by shRNA to $\beta$-catenin $[14,15]$ displayed a capability to dramatically alleviate silica-induced fibrosis in a silicosis mouse model [16]. Such attenuation of silica-induced pulmonary fibrosis by targeting $\mathrm{Wnt} / \beta$-catenin signaling was also reported in silicosis rats that were administrated with rat bone marrow mesenchymal stromal cells (BMSCs) [16]. In line with the above findings, an enhanced $\mathrm{Wnt} / \beta$-catenin signaling, along with the increased abundance of NOX4 and profibrogenic proteins but reduced DKK1, was also observed in a $\mathrm{SiO}_{2}$-induced silicosis mouse lung, and BEAS-2B human lung epithelial cells exposed to $\mathrm{SiO}_{2}$.

Repeated oxidative stress is one of the detrimental factors of lung injury. The NOX-mediated overproduction of ROS due to excessive stimulation of proinflammatory cytokines or environmental insults such as silica dusts causes a major part of oxidative stress in the lungs. Among different iso- forms of NOXs, the pathophysiological roles of NOX4 isoform have a great implication in lung epithelial cell death, (myo)fibroblast differentiation, and collagen deposition [23, $25,41]$. In this regard, an elevated NOX4 was observed in hyperplastic alveolar type II cells and contributed to the cell death and robustly expressed in pulmonary fibroblasts of IPF patients and epithelial cells $[25,26]$. Experimentally, mice with deficient NOX4 exhibited a significantly less severe fibrotic phenotype in the lungs of a bleomycin-induced pulmonary fibrosis mouse model [25], suggesting that NOX4 was a potential target for treatment of pulmonary fibrosis including silicosis. Indeed, in a previous study examining the effect of Tanshinone IIA (Tan IIA), a natural compound of traditional Chinese medicine in a silicosis rat model, Feng et al. found that Tan IIA could significantly alleviate the silica-induced pulmonary fibrosis, by reducing the silicaaugmented NOX4 and enhancing Nrf2/ARE antioxidant activity in the lung of silicosis rats [42]. In this report, an increased expression of NOX4 and ROS production was also observed in BEAS-2B lung epithelial cells in response to $\mathrm{SiO}_{2}$ stimulations. Of note, the shRNA-mediated knockdown of NOX4 led to a significant decrease of $\mathrm{SiO}_{2}$-induced profibrogenic molecules ( $\alpha$-SMA, vimentin) in lung epithelial cells.

An increasing number of evidences have demonstrated a crosstalk of Wnt $/ \beta$-catenin and ROS in the regulation of cell 
proliferation and differentiation [43-46]. For example, a previous study has shown that $\mathrm{Wnt} / \beta$-catenin was able to modulate redox regulatory protein $\mathrm{p} 66(\mathrm{Shc})$, which in turn regulate a NOX4-mediated ROS and ultimately lead to vascular endothelial dysfunction [43]. In this context, the Wnt3a-induced Wnt signaling, NOX4 expression, and ROS production could be inhibited by p66(Shc) knockdown and antioxidant NAC, whereas an overexpression of p66(Shc) enhanced Wnt signaling. A constitutive activation of Wnt $\beta$ catenin in the endothelium resulted in an increased vascular ROS production and endothelial dysfunction [43]. In contrast, ROS also show a capacity in modulating $\mathrm{Wnt} / \beta$-catenin signaling in mouse extraembryonic endoderm patterning; a sustained exposure of $\mathrm{H}_{2} \mathrm{O}_{2}$ (ROS) enhanced Wnt/ $\beta$-catenin activity in retinoic acid-treated F9 teratocarcinoma cells and promoted cell differentiation into primitive endoderm, while exposure of these cells to antioxidant NAC impeded cell differentiation [44]. Similarly, the cell oxidative injury induced by a reactivation of $\mathrm{Wnt} / \beta$-catenin signaling was also observed in podocyte dysfunction, and a podocytespecific knockout of $\beta$-catenin protected podocytes from injury and albuminuria induced by advanced oxidation protein products in mice. Mechanistically, the Wnt/ $\beta$-catenin exerted its function by inducing the receptor of advanced glycation end products- (RAGE-) mediated NOX expression, ROS production, and activation of nuclear factor-kappaB $(\mathrm{NF} \kappa \mathrm{B})$ [45]. Such a NOX-mediated regulation of $\mathrm{Wnt} / \beta$ catenin was also reported in intestinal and colon epithelial cells, in which the NOX1 regulated Wnt signaling in a redox-dependent manner [46]. In consonance with the above findings, in the present study, the crosstalk of $\mathrm{Wnt} / \beta$-catenin and NOX4 was also found in BEAS-2B lung epithelial cells in response to silica dust exposure. The Wnt3a-activated $\mathrm{Wnt} / \beta$-catenin signaling augmented NOX4 expression and ROS production and reduced GSH production, accompanied by an increased expression of profibrogenic proteins; conversely, the DKK1-mediated inhibition of $\mathrm{Wnt} / \beta$-catenin exerted an opposite effect of Wnt3a on lung epithelial cells exposed to $\mathrm{SiO}_{2}$. Vice versa, an overexpression of NOX4 enhanced $\mathrm{Wnt} / \beta$-catenin signaling activity, along with an augmentation of profibrogenic proteins in cells. NOX4 also reduced GSH production and increased the expression of Nrf2, a key intracellular antifibrotic factor that maintains the homeostasis of ECM [47], while the shRNA-mediated knockdown of NOX4 demonstrated an opposite effect of NOX4 overexpression. This result was in agreement with the finding in cystic fibrosis transmembrane conductance regulator (CFTR) defected cells with ROS overproduction [48]. It is worthwhile to note that the overexpression of NOX4 suppressed the DKK1 expression. This observation was in line with the result of the reduction of DKK1 in the lung of silicosis mice (Figure 1(b)), implying that the overwhelming silica-induced NOX4 in the silicotic lungs might inhibit the DKK1 expression. This result thus suggests that DKK1 may be a novel target in silicosis, which requires further investigation.

In addition, reduced glutathione (GSH) is a ubiquitous tripeptide thiol, which has been recognized as a protective antioxidant against oxidative stresses [49]. A deficiency of

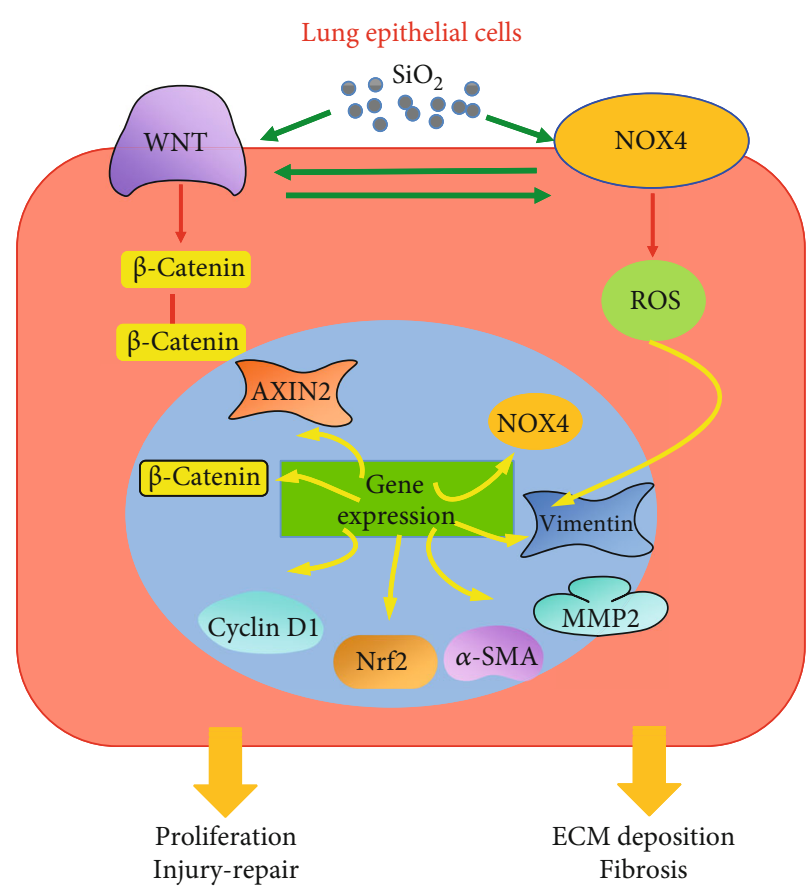

FIgURE 7: A schematic mechanism of interaction between Wnt $\beta$ catenin and NOX4 signaling in $\mathrm{SiO}_{2}$-induced epithelialmesenchymal transition in lung epithelial cells. The exposure of silica dust activated $\mathrm{Wnt} / \beta$-catenin signaling and induced NOX4 expression in lung epithelial cells, substantially promoted the expression of Wnt target genes for epithelial cell proliferation and injury repair, and increased ROS production and expression of extracellular matrix (ECM) and fibrogenic factors to promote fibrogenesis. However, the activation of $\mathrm{Wnt} / \beta$-catenin signaling also induced NOX4 expression that resulted in an overwhelming ROS production and further caused epithelial cell injury. Vice versa, the NOX4 (or ROS) was able to in turn enhanced Wnt/ $\beta$ catenin signaling which further induced NOX4 expression. In this context, the Wnt $/ \beta$-catenin signaling and NOX4 formed a positive forward loop to promote lung epithelial injury and EMT, ECM deposition, and fibrogenesis in response to a continuous exposure of silica dust.

GSH in the lower respiratory tract was thought to have an important implication in the progression of IPF [50]; it was downregulated in bleomycin-induced lung fibrosis in a mouse [51] and PM2.5-induced pulmonary fibrosis lung in rats [52]. In this study, a Wnt/ $\beta$-catenin-mediated decline of reduced glutathione (GSH) was also determined in lung epithelial cells, which was in line with findings in lens epithelial cells [53], zebrafish ZF4 cells [54], and murine macrophage-like RWA264.7 cells [55]. Taken together, these data suggest that a positive forward loop between $\mathrm{Wnt} / \beta$ catenin and NOX4 promotes the EMT and fibrogenesis in lung epithelial cells in response to the exposure of silica dust.

\section{Conclusion}

Collectively, in the present study, the crosstalk between canonical Wnt signaling and NOX4 was investigated in BEAS-2B human lung epithelial cells in response to $\mathrm{SiO}_{2}$ particles. The in vivo results demonstrated an enhanced activity 
of Wnt/ $\beta$-catenin and NOX4 signaling in $\mathrm{SiO}_{2}$-induced mouse silicosis lungs. The in vitro study revealed the inhibition of cell proliferation, along with enhanced Wnt/ $\beta$ catenin signaling activity, increased ROS production, expression of NOX4, and profibrogenic proteins in BEAS2B cells exposed to $\mathrm{SiO}_{2}$. A molecular study further demonstrated the crosstalk between canonical Wnt/ $\beta$-catenin signaling and NOX4 in lung epithelial cells exposed to silica dust; an activation of $\mathrm{Wnt} / \beta$-catenin signaling increased NOX4 and ROS production but reduced GSH; vice versa, an increased NOX4 enhanced the canonical Wnt signaling. Mechanistically, the Nrf2-mediated antioxidant activity may be involved in the interaction between the $\mathrm{Wnt} / \beta$ catenin and NOX4 signaling and play roles in the EMT and fibrogenic processes of lung epithelial cells in response to a silica exposure (Figure 7). These findings imply that a positive feed forward loop between $\mathrm{Wnt} / \beta$-catenin and NOX4 signaling promotes EMT property in BEAS-2B cells exposed to silica stimulation, which thus emphasize the profibrogenic role of the crosstalk of Wnt and NOX-mediated ROS in lung epithelial cell injury and development of silicosis, which warrants further investigations.

$\begin{array}{ll}\text { Abbreviations } \\ \text { ALI: } & \text { Acute lung injury carcinoma } \\ \text { ARDS: } & \text { Acute respiratory distress syndrome } \\ \text { ARE: } & \text { Antioxidant response element } \\ \text { BAX: } & \text { Bcl-2-associated X } \\ \text { Bcl-2: } & \text { B cell lymphoma-2 } \\ \text { BM: } & \text { Bone marrow } \\ \text { BMSCs: } & \text { Bone marrow mesenchymal stem cells } \\ \text { CM: } & \text { Conditioned medium } \\ \text { ECL: } & \text { Enhanced chemiluminescence } \\ \text { EVs: } & \text { Extracellular vesicles } \\ \text { hfPMSCs: } & \text { Human fetal placental mesenchymal stem cells } \\ \text { HGF: } & \text { Hepatocyte growth factor } \\ \text { HO-1: } & \text { Glutathione peroxidase } \\ \text { keap1: } & \text { Kelch-like ECH-associated protein } 1 \\ \text { Nrf2: } & \text { Nuclear factor erythroid 2-related factor } 2 \\ \text { MSCs: } & \text { Mesenchymal stem cells } \\ \text { PVECs: } & \text { Pulmonary microvascular endothelial cells } \\ \text { ROS: } & \text { Reactive oxygen species } \\ \text { SLE: } & \text { Systemic lupus erythematosus } \\ \text { T-AOC: } & \text { Total antioxidative capacity. }\end{array}$

\section{Data Availability}

All data generated or analyzed during this study are included in this published article.

\section{Ethical Approval}

The study and protocol were approved by the ethics committee for conduction of biological research at the College of Life Science of Ningxia University (NXULS20180123-3).

\section{Disclosure}

The funders had no role in study design, data collection and analysis, decision to publish, or preparation of the manuscript.

\section{Conflicts of Interest}

The authors declared that they have no competing interests.

\section{Authors' Contributions}

Jia Ma and Qian Cai contributed equally to this work. X.L. and F.L. conceived and designed the experiments; J.M. and Q.C. conducted the experiments, analyzed data, and drafted the manuscript; D.Y., J.Y., J.X., M.Y., Y.L., and F.M. performed experiments and acquired data; J.M. and Q.C. drafted the manuscript; X.L. and F.L. interpreted data and critically revised the manuscript. All authors read and approved the final version of the manuscript.

\section{Acknowledgments}

This work was financially supported by grants from the National Natural Science Foundation of China (31860318, 32070863 , and 81860566) and a grant from the National Natural Science Foundation of Ningxia Hui Autonomous Region (NZ17169).

\section{Supplementary Materials}

Suppl. Table S1: primary and secondary antibodies used for immunostaining. Suppl. Table S2: primary and secondary antibodies used for Western blotting. (Supplementary Materials)

\section{References}

[1] C. C. Leung, I. T. S. Yu, and W. Chen, "Silicosis," Lancet, vol. 379, no. 9830, pp. 2008-2018, 2012.

[2] L. E. Fazen, B. Linde, and C. A. Redlich, "Occupational lung diseases in the 21st century: the changing landscape and future challenges," Current Opinion in Pulmonary Medicine, vol. 26, no. 2, pp. 142-148, 2020.

[3] N. Wu, C. Xue, S. Yu, and Q. Ye, “Artificial stone-associated silicosis in China: a prospective comparison with natural stone-associated silicosis," Respirology, vol. 25, no. 5, pp. 518-524, 2020.

[4] H. Barnes, N. S. L. Goh, T. L. Leong, and R. Hoy, "Silica-associated lung disease: an old-world exposure in modern industries," Respirology, vol. 24, no. 12, pp. 1165-1175, 2019.

[5] R. F. Hoy and D. C. Chambers, "Silica-related diseases in the modern world," Allergy, vol. 75, no. 11, pp. 2805-2817, 2020.

[6] M. Sauler, I. S. Bazan, and P. J. Lee, "Cell death in the lung: the apoptosis-necroptosis axis," Annual Review of Physiology, vol. 81, no. 1, pp. 375-402, 2019.

[7] B. R. O. O. K. E. T. MOSSMAN and A. N. D. R. E. W. CHURG, "Mechanisms in the pathogenesis of asbestosis and silicosis," American Journal of Respiratory and Critical Care Medicine, vol. 157, no. 5, pp. 1666-1680, 1998. 
[8] J. Qu, L. Yue, J. Gao, and H. Yao, "Perspectives on Wnt signal pathway in the pathogenesis and therapeutics of chronic obstructive pulmonary disease," The Journal of Pharmacology and Experimental Therapeutics, vol. 369, no. 3, pp. 473-480, 2019.

[9] J. Shi, F. Li, M. Luo, J. Wei, and X. Liu, "Distinct roles of Wnt/ $\beta$ -catenin signaling in the pathogenesis of chronic obstructive pulmonary disease and idiopathic pulmonary fibrosis," Mediators of Inflammation, vol. 2017, Article ID 3520581, 16 pages, 2017.

[10] B. N. Zhang, X. Zhang, H. Xu et al., "Dynamic variation of RAS on silicotic fibrosis pathogenesis in rats," Current Medical Science, vol. 39, no. 4, pp. 551-559, 2019.

[11] V. Aumiller, N. Balsara, J. Wilhelm, A. Günther, and M. Königshoff, "WNT/ $\beta$-catenin signaling induces IL- $1 \beta$ expression by alveolar epithelial cells in pulmonary fibrosis," American Journal of Respiratory Cell and Molecular Biology, vol. 49, no. 1, pp. 96-104, 2013.

[12] H. A. Baarsma and M. Konigshoff, "'WNT-er is coming': WNT signalling in chronic lung diseases," Thorax, vol. 72, no. 8, pp. 746-759, 2017.

[13] T. N. Perkins, M. A. Dentener, F. R. Stassen et al., "Alteration of canonical and non-canonical WNT-signaling by crystalline silica in human lung epithelial cells," Toxicology and Applied Pharmacology, vol. 301, pp. 61-70, 2016.

[14] W. Dai, F. Liu, C. Li et al., "Blockade of Wnt/ $\beta$-catenin pathway aggravated silica-induced lung inflammation through Tregs regulation on Th immune responses," Mediators of Inflammation, vol. 2016, Article ID 6235614, 14 pages, 2016.

[15] X. Wang, W. Dai, Y. Wang, Q. Gu, D. Yang, and M. Zhang, "Blocking the Wnt/ $\beta$-catenin pathway by lentivirus-mediated short hairpin RNA targeting $\beta$-catenin gene suppresses silica-induced lung fibrosis in mice," International Journal of Environmental Research and Public Health, vol. 12, no. 9, pp. 10739-10754, 2015.

[16] E. Zhang, Y. Yang, S. Chen et al., "Bone marrow mesenchymal stromal cells attenuate silica-induced pulmonary fibrosis potentially by attenuating $\mathrm{Wnt} / \beta$-catenin signaling in rats," Stem cell research \& therapy, vol. 9, no. 1, pp. 311-311, 2018.

[17] G. N. Joshi, A. M. Goetjen, and D. A. Knecht, "Silica particles cause NADPH oxidase-independent ROS generation and transient phagolysosomal leakage," Molecular Biology of the Cell, vol. 26, no. 18, pp. 3150-3164, 2015.

[18] K. Bedard and K. H. Krause, "The NOX family of ROSgenerating NADPH oxidases: physiology and pathophysiology," Physiological Reviews, vol. 87, no. 1, pp. 245-313, 2007.

[19] M. Bocchino, S. Agnese, E. Fagone et al., "Reactive oxygen species are required for maintenance and differentiation of primary lung fibroblasts in idiopathic pulmonary fibrosis," PLoS One, M. Koenigshoff, Ed., vol. 5, no. 11, p. e14003, 2010.

[20] P. S. Hsu, C. M. Lin, J. F. Chang et al., "Participation of NADPH oxidase-related reactive oxygen species in leptinpromoted pulmonary inflammation: regulation of cPLA $2 \alpha$ and COX-2 expression," International Journal of Molecular Sciences, vol. 20, no. 5, p. 1078, 2019.

[21] K. Nakashima, T. Sato, S. Shigemori, T. Shimosato, M. Shinkai, and T. Kaneko, "Regulatory role of heme oxygenase-1 in silicainduced lung injury," Respiratory Research, vol. 19, no. 1, pp. 144-144, 2018.
[22] W. M. Nauseef, "Biological roles for the NOX family NADPH oxidases," The Journal of Biological Chemistry, vol. 283, no. 25, pp. 16961-16965, 2008.

[23] L. Hecker, R. Vittal, T. Jones et al., "NADPH oxidase-4 mediates myofibroblast activation and fibrogenic responses to lung injury," Nature Medicine, vol. 15, no. 9, pp. 1077-1081, 2009.

[24] I. T. Lee and C. M. Yang, "Role of NADPH oxidase/ROS in pro-inflammatory mediators-induced airway and pulmonary diseases," Biochemical Pharmacology, vol. 84, no. 5, pp. 581590, 2012.

[25] S. Carnesecchi, C. Deffert, Y. Donati et al., "A key role for NOX4 in epithelial cell death during development of lung fibrosis," Antioxidants \& Redox Signaling, vol. 15, no. 3, pp. 607-619, 2011.

[26] N. Amara, D. Goven, F. Prost, R. Muloway, B. Crestani, and J. Boczkowski, "NOX4/NADPH oxidase expression is increased in pulmonary fibroblasts from patients with idiopathic pulmonary fibrosis and mediates TGF $\beta 1$-induced fibroblast differentiation into myofibroblasts," Thorax, vol. 65, no. 8, pp. 733-738, 2010.

[27] E. R. Jarman, V. S. Khambata, C. Cope et al., "An inhibitor of NADPH oxidase-4 attenuates established pulmonary fibrosis in a rodent disease model," American Journal of Respiratory Cell and Molecular Biology, vol. 50, no. 1, pp. 158-169, 2014.

[28] F. Liu, J. Liu, D. Weng et al., "CD4+CD25+Foxp3+ regulatory $\mathrm{T}$ cells depletion may attenuate the development of silicainduced lung fibrosis in mice," PLoS One, D. Unutmaz, Ed., vol. 5, no. 11, p. e15404, 2010.

[29] H. Li, N. Ma, J. Wang et al., "Nicotine induces progressive properties of lung adenocarcinoma A549 cells by inhibiting cystic fibrosis transmembrane conductance regulator (CFTR) expression and plasma membrane localization," Technology in Cancer Research \& Treatment, vol. 17, p. $1533033818809984,2018$.

[30] M. Komai, K. Mihira, A. Shimada et al., "Pathological study on epithelial-mesenchymal transition in silicotic lung lesions in rat," Veterinary Sciences, vol. 6, no. 3, p. 70, 2019.

[31] D. Burtenshaw, R. Hakimjavadi, E. Redmond, and P. Cahill, "Nox, reactive oxygen species and regulation of vascular cell fate," Antioxidants, vol. 6, no. 4, p. 90, 2017.

[32] R. C. Chambers and P. F. Mercer, "Mechanisms of alveolar epithelial injury, repair, and fibrosis," Annals of the American Thoracic Society, vol. 12, Supplement 1, pp. S16-S20, 2015.

[33] X. Wang, K. Xu, X. Y. Yang, J. Liu, Q. Zeng, and F. S. Wang, "Upregulated miR-29c suppresses silica-induced lung fibrosis through the Wnt/ $\beta$-catenin pathway in mice," Human \& Experimental Toxicology, vol. 37, no. 9, pp. 944-952, 2017.

[34] E. Amjad, S. Asnaashari, and B. Sokouti, "The role of associated genes of Wnt signaling pathway in chronic obstructive pulmonary disease (COPD)," Gene Reports, vol. 18, p. 100582, 2020.

[35] M. Konigshoff and O. Eickelberg, "WNT signaling in lung disease," American Journal of Respiratory Cell and Molecular Biology, vol. 42, no. 1, pp. 21-31, 2010.

[36] B. L. M. Hogan, C. E. Barkauskas, H. . A. Chapman et al., "Repair and regeneration of the respiratory system: complexity, plasticity, and mechanisms of lung stem cell function," Cell Stem Cell, vol. 15, no. 2, pp. 123-138, 2014.

[37] M. Lehmann, H. A. Baarsma, and M. Konigshoff, "WNT signaling in lung aging and disease," Annals of the American Thoracic Society, vol. 13, Supplement 5, pp. S411-S416, 2016. 
[38] M. Königshoff, N. Balsara, E.-M. Pfaff et al., "Functional Wnt signaling is increased in idiopathic pulmonary fibrosis," PLoS One, H. H. H. W. Schmidt, Ed., vol. 3, no. 5, p. e2142, 2008.

[39] X. X. Jia, T. T. Zhu, Y. Huang, X. X. Zeng, H. Zhang, and W. X. Zhang, "Wnt/ $\beta$-catenin signaling pathway regulates asthma airway remodeling by influencing the expression of c-Myc and cyclin D1 via the p38 MAPK-dependent pathway," Experimental and Therapeutic Medicine, vol. 18, no. 5, pp. 34313438, 2019.

[40] E. E. Morrisey, "Wnt signaling and pulmonary fibrosis," The American Journal of Pathology, vol. 162, no. 5, pp. 13931397, 2003.

[41] F. Jiang, G. S. Liu, G. J. Dusting, and E. C. Chan, "NADPH oxidase-dependent redox signaling in TGF- $\beta$-mediated fibrotic responses," Redox Biology, vol. 2, pp. 267-272, 2014.

[42] F. Feng, P. Cheng, H. Zhang et al., "The protective role of tanshinone IIA in silicosis rat model via TGF- $\beta 1 /$ Smad signaling suppression, NOX4 inhibition and Nrf2/ARE signaling activation," Drug Design, Development and Therapy, vol. Volume 13, pp. 4275-4290, 2019.

[43] A. Vikram, Y. R. Kim, S. Kumar et al., "Canonical Wnt signaling induces vascular endothelial dysfunction via p66Shc-regulated reactive oxygen species," Arteriosclerosis, Thrombosis, and Vascular Biology, vol. 34, no. 10, pp. 2301-2309, 2014.

[44] J. W. H. Wen, J. T. K. Hwang, and G. M. Kelly, "Reactive oxygen species and Wnt signalling crosstalk patterns mouse extraembryonic endoderm," Cellular Signalling, vol. 24, no. 12, pp. 2337-2348, 2012.

[45] L. Zhou, X. Chen, M. Lu et al., "Wnt/ $\beta$-catenin links oxidative stress to podocyte injury and proteinuria," Kidney International, vol. 95, no. 4, pp. 830-845, 2019.

[46] S. Kajla, A. S. Mondol, A. Nagasawa et al., “A crucial role for Nox 1 in redox-dependent regulation of Wnt- $\beta$-catenin signaling," The FASEB Journal, vol. 26, no. 5, pp. 2049-2059, 2012.

[47] J. Wei, H. Zhu, G. Lord et al., "Nrf2 exerts cell-autonomous antifibrotic effects: compromised function in systemic sclerosis and therapeutic rescue with a novel heterocyclic chalcone derivative," Translational Research, vol. 183, pp. 71-86.e1, 2017.

[48] L. de Bari, M. Favia, A. Bobba, R. Lassandro, L. Guerra, and A. Atlante, "Aberrant GSH reductase and NOX activities concur with defective CFTR to pro-oxidative imbalance in cystic fibrosis airways," Journal of Bioenergetics and Biomembranes, vol. 50, no. 2, pp. 117-129, 2018.

[49] I. Rahman and W. MacNee, "Oxidative stress and regulation of glutathione in lung inflammation," The European Respiratory Journal, vol. 16, no. 3, pp. 534-554, 2000.

[50] K. M. Beeh, J. Beier, I. C. Haas, O. Kornmann, P. Micke, and R. Buhl, "Glutathione deficiency of the lower respiratory tract in patients with idiopathic pulmonary fibrosis," The European Respiratory Journal, vol. 19, no. 6, pp. 11191123, 2002.

[51] S. S. Iyer, A. M. Ramirez, J. D. Ritzenthaler et al., "Oxidation of extracellular cysteine/cystine redox state in bleomycininduced lung fibrosis," American Journal of Physiology. Lung Cellular and Molecular Physiology, vol. 296, no. 1, pp. L37L45, 2009.

[52] B. Sun, Y. Shi, Y. Li et al., "Short-term PM2.5 exposure induces sustained pulmonary fibrosis development during post- exposure period in rats," Journal of Hazardous Materials, vol. 385, p. 121566, 2020.

[53] Z. Wei, J. Caty, J. Whitson et al., "Reduced glutathione level promotes epithelial-mesenchymal transition in lens epithelial cells via a Wnt/ $\beta$-catenin-mediated pathway," The American Journal of Pathology, vol. 187, no. 11, pp. 2399-2412, 2017.

[54] Z. Liu, Y. Liu, Y. Gu et al., "Met-enkephalin inhibits ROS production through $\mathrm{Wnt} / \beta$-catenin signaling in the ZF4 cells of zebrafish," Fish \& Shellfish Immunology, vol. 88, pp. 432-440, 2019.

[55] X. Wu, G. Deng, M. Li et al., "Wnt/ $\beta$-catenin signaling reduces Bacillus Calmette-Guerin-induced macrophage necrosis through a ROS -mediated PARP/AIF-dependent pathway," BMC Immunology, vol. 16, no. 1, 2015. 